IZA DP No. 4486

SME Policy and Firms' Productivity in Latin America

Pablo Ibarrarán

Alessandro Maffioli

Rodolfo Stucchi

October 2009 


\title{
SME Policy and Firms' Productivity in Latin America
}

\author{
Pablo Ibarrarán \\ Inter-American Development Bank \\ and IZA \\ Alessandro Maffioli \\ Inter-American Development Bank \\ Rodolfo Stucchi \\ Inter-American Development Bank
}

Discussion Paper No. 4486

October 2009

\author{
IZA \\ P.O. Box 7240 \\ 53072 Bonn \\ Germany \\ Phone: +49-228-3894-0 \\ Fax: +49-228-3894-180 \\ E-mail: iza@iza.org
}

\begin{abstract}
Any opinions expressed here are those of the author(s) and not those of IZA. Research published in this series may include views on policy, but the institute itself takes no institutional policy positions.

The Institute for the Study of Labor (IZA) in Bonn is a local and virtual international research center and a place of communication between science, politics and business. IZA is an independent nonprofit organization supported by Deutsche Post Foundation. The center is associated with the University of Bonn and offers a stimulating research environment through its international network, workshops and conferences, data service, project support, research visits and doctoral program. IZA engages in (i) original and internationally competitive research in all fields of labor economics, (ii) development of policy concepts, and (iii) dissemination of research results and concepts to the interested public.
\end{abstract}

IZA Discussion Papers often represent preliminary work and are circulated to encourage discussion. Citation of such a paper should account for its provisional character. A revised version may be available directly from the author. 
IZA Discussion Paper No. 4486

October 2009

\section{ABSTRACT}

\section{SME Policy and Firms' Productivity in Latin America*}

Very little is known about the effectiveness of SME policies, and a careful look at the structure, mechanisms and incentives provided by these policies suggest caution in their implementation and, most importantly, the need to carefully and closely monitor their results. This paper relies on the microeconometric analysis of a homogeneous dataset of sixteen Latin American and Caribbean countries to analyze the magnitude and determinants of the productivity gap between large and SME firms and to simulate of the impact on productivity of various policy scenarios.

JEL Classification: D24, L53, L60, O38, O54

Keywords: $\quad$ SMEs, SME policy, productivity, Latin America

Corresponding author:

Pablo Ibarrarán

Office of Strategic Planning and Development Effectiveness

Inter-American Development Bank

1300 New York Avenue

Washington, DC 20577

USA

E-mail: pibarraran@iadb.org

\footnotetext{
* The views expressed in this paper are those of the authors and do not necessarily represent those of the Inter-American Development Bank.
} 


\section{Introduction}

In the last decades, governments have spent an increasing amount of resources in policies to support small and medium enterprises (SMEs). The extended use of these policies may be justified based on some of the challenges that SMEs face and that could hinder their productivity and growth. However, very little is known about the effectiveness of these policies, and a careful look at the structure, mechanisms and incentives provided by SME policies suggest caution in their implementation and, most importantly, the need to carefully and closely monitor their results.

As in most public policies, strong opinions exist in favor and against SME support programs. On one hand, it has been argued that SMEs employ a large proportion of the population and therefore by subsidizing SMEs more employment will be created. It has also been argued that SME policies can promote growth and reduce poverty. Defenders of these policies argue that SMEs are more flexible, more dynamic, and more productive than large firms, even though they are usually constrained by specific market failures, which requires specific policies. On the other hand, detractors point out that these policies generate distortions that affect the allocation of resources and affect the size distribution of firms, and thus may have a negative effect on productivity. Also, those against the widespread use of SME policies point to the lack of documented results on the effectiveness of such interventions.

The relationship between size and productivity is of particular interest in Latin America and Caribbean (LAC) countries. There is a wide consensus that the difference in the growth rate of the GDP per capita between LAC countries and the rest of western economies is due to low productivity growth rates (see Cole et al 2005). This fact, plus the fact that a large percentage of establishments are small but they account for a relatively small share of production, calls for a deeper understanding of the relationship between size and productivity and of the role played by SME policy in the region.

In this paper we discuss the relationship between firm size and productivity in LAC and provide a framework to guide the analysis of the rationale, structure and potential impacts of the SME policies on the aggregate level of productivity. This analytical framework assumes that SME policies might affect the aggregate level of productivity through two channels: first, SME policies can affect aggregate productivity by directly influencing the productivity of SMEs; second, if SMEs and large firms differ in productivity (and there is ample evidence that they do significantly), SME policies can influence aggregate productivity through the reallocation of resources across SME and large firms.

We perform three empirical exercises using comparable data for sixteen LAC countries. We first compare the productivity of SMEs with that of large firms. Second, we study how the variables that can be affected by SME policy such as training, access to credit, product innovation, and ISO certification affect the productivity gap. Finally, the third exercise 
simulates the effect of several policy scenarios on the productivity of SMEs and aggregate productivity.

We use plant level data for sixteen LAC countries from the World Bank Enterprise Surveys (WBES) dataset. The principal advantage of WBES is that it provides homogeneous information for all the countries. The use of comparable micro data for all the countries is an important advantage with respect to previous studies in the region. Those studies used micro level data for only a small set of countries or aggregate data constructed from different sources that in many cases were not comparable between countries. In most of the LAC countries, WBES provides us with a cross-section of plants for the period 2006. However, for some countries the information is for the period 2003 and for a reduced group of countries 2003 and 2006. Because of the lack of panel data information, we estimate plant's productivity using non-parametric techniques that assume constant returns to scale (CRS). This assumption can be problematic when comparing firms of different scale. To overcome this limitation we analyze the robustness of our results by considering different values of the parameter of returns to scale. As an additional robustness check, we estimate the production function without assuming CRS. This would be the preferred method but with cross-section data it is hard to find proper instruments for the inputs.

The findings reported here show that, as expected, large enterprises tend to be more productive than SMEs. On the determinants of this productivity gap, some key associated factors are the different levels of use of credit, use of training, intensity of innovation and quality certification, all variables related to firms' acquisition of improved technologies Unfortunately, data constraints precludes distinguishing whether the positive correlation between productivity and these factors is driven by selection of more productive firms into these activities or whether it reflects the effect of these activities on the productivity of SMEs. Finally, a micro-simulation analysis shows that properly targeted SME policies might have a significant positive effect on aggregate productivity, mostly because of reallocation of resources toward more productive firms. However, the results of the simulation also suggest that the same policies not specifically targeted at SMEs, but applied to all firms, might produce a higher increase of aggregate productivity.

The main contribution of this study to the literature on SMEs and productivity in LAC is to systematically reexamine the topics for a large number of LAC countries using a consistent methodology and comparable data. This work is related to Van Biesebroeck (2005) who studied growth and productivity growth in African manufacturing with particular focus on firms's size. For LAC countries the evidence is scarce and mainly focused in few countries (Peres and Stumpo, 2000; Liedholm, 2002; Alvarez and Crespi, 2003, OECD 2007, and Goldberg and Palladini, 2007).

The rest of the paper is organized as follows. Section 2 discusses the objectives, rationale, and instruments of the SME policy. It also presents a review some of the SME policies applied in LAC countries. Section 3 presents the relationship between firm size and productivity. Section 4 presents the dataset. Section 5 presents evidence on the productivity gap between SMEs and large firms. Section 6 discusses the determinants of the gap. Section 7 simulates several policy scenarios. Section 8 discusses the evidence on the effectiveness of the SME policy. Finally, section 9 concludes. 


\section{The SME Sector and SME Policies: Objectives, Rationale, and Instruments}

\subsection{The SME sector in Latin America and the Caribbean}

The relative size of the SME sector varies across countries and it is an endogenous characteristic of each country. The endowment of natural resources, technology, policies, and institutions help determine a nation's industrial composition and optimal firm size. For instance, some countries may have endowments that give the country a comparative advantage in the production of goods that are produced efficiently in large firms, while other countries may have a comparative advantage in goods produced more efficiently in small firms (You, 1995). Similarly, countries that are open to international trade may have larger optimal firm size than countries that are less integrated internationally (Caves et al. 1980). In addition, the firm size distribution can also be affected by economic policy. For example, simplified tax regimes for SMEs may affect their incentives to grow, as firms may not find it profitable to move to the standard tax regime.

International comparisons of the size of the SME sector are affected by the particular definition of SME. SMEs are those firms with a quantitative measure, e.g. number of employees, lower than a certain threshold. However, not all the countries use the same quantitative measure. Moreover, those that use the same quantitative measure do not necessarily use the same threshold. The quantitative measures used LAC countries include number of employees, sales, assets, and a combination of these criteria. The most commonly criteria used to define SMEs are number of employees and monthly or annual sales. In general, the upper limit of the number of employees used in the SME definition in LAC countries is lower than in EU countries and US. The exceptions are the manufacturing sectors in Brazil with a limit of 500 -equal to the one in US- and Mexico with a limit of 250 employees -equal of the one in the EU. ${ }^{4}$

\section{[TABLE 1 ABOUT HERE]}

As shown in Table 1, the largest fraction of small firms is composed of very small firms, those with less than five or ten employees, and that constitute the "micro" firms in the context of the MSME sector. Because data constraints our empirical analysis focuses on the SME sector, namely those with five or more employees.

$4 \quad$ According with the EU definition, a SME is a non-subsidiary and independent firm that employs less than 250 employees and has an annual turnover lower than EUR 50 millions or an annual balance sheet lower than EUR 43 millions. 


\subsection{SME Policies and Instruments}

SME policies are those targeted at firms below a certain size. With this broad definition, a wide range of policies falls in this category. In general, almost all LAC countries have a simplified tax regime or differential labor regulations for SMEs, as well as programs to facilitate access to credit and a set of subsidies and services aimed at supporting SMEs in different aspects of their activities. This chapter centers on those policies aimed at increasing firms' productivity, most often through the promotion of training, innovation, and quality certification. Although access to credit has been analyzed in another chapter of the report, it will also be discussed here as it is an instrument widely adopted in SME policies.

Most of SME policies mention as their goal the achievement of higher rates of economic growth and the reduction of poverty. ${ }^{5}$ However, they often have other objectives, such as employment, in addition to the two ones mentioned. In general those objectives are not clearly specified. Additionally, when designing and implementing SME policies, policy makers are often faced with restrictions and incentives that go beyond concerns about market failures, and that are more related to political cycles, equality, and other concepts in the realm of political economy. These features should be acknowledged when examining the coherence of SME interventions.

From an economic point of view, there are two broad sets of justifications for SME policies. The main economic justification is the existence of market failures that might stunt growth of SMEs, which in turn can lead to lower aggregate growth. In this context, public interventions targeted at SMEs are justified in terms of addressing market failures that affect SME, such as asymmetric and/or incomplete information, non-convexities, and local externalities. For instance in the financial market, banks often fail to accurately assess the risk of lending to SME and therefore reject some profitable projects and compromise the survival and growth of many promising firms. Therefore, by removing information asymmetries that preclude access to financing, economic policy may enhance the growth of the most efficient firms and a net gain in terms of productivity. In some cases owners of small firms do not have information on the private benefits of taking certain courses of action, e.g., offering training to their employees or obtaining external advice from specialists or consultant, illustrating instances of incomplete information. In other cases, those actions are not taken because of scale problems, suggesting failures related to indivisibilities and non-convexities. In this context, SME efficiency may be constrained by the incapacity or unwillingness of crucial suppliers to scale down their services to meet the demand of smaller firms. The most common example is perhaps the provision of small loans by credit institutions, but the concept could be expanded to several services that imply an initial assessment of the costumer needs and characteristics (such, for instance, technical assistance and training). In these cases, the fixed costs of providing the services do not significantly decrease with the size of the clients, while the revenues decrease significantly, making the provision of services to smaller firms highly unprofitable. This

\footnotetext{
${ }^{5}$ See Ayyagari et al. (2007).
} 
argument has frequently been used to justify public policies that aim at supporting the coordination efforts that the SMEs need to undertake in order to organize a joint demand for services. Associativity, networking and clustering policies, for instance, have often been justified for this reason, among others. ${ }^{6}$

The other set of justifications for SME policies relate to the (presumed or real) characteristics of SMEs that are deemed particularly desirable. First, it is argued that SMEs enhance competition and entrepreneurship and hence have external benefits on economywide efficiency, innovation, and aggregate productivity growth. These externalities would justify public support to SMEs. Second, SMEs are portrayed as labor-intensive, thus an expansion of the SME sector would boost employment more than an expansion of large firms. Finally, proponents claim that SMEs may be efficient firms in an early stage of development, whose growth is constrained by institutional failures that favor large firms.

There are also skeptical views questioning the efficacy of SME support policies. First, some authors stress the advantages of large firms, for example, arguing that large firms benefit from economies of scale and create more stable and higher quality jobs. Second, some research finds that SMEs are neither more labor intensive, nor better at job creation than large firms. Third, other authors question the validity of considering firm size as an exogenous determinant of economic growth. According with this view, pro-SME subsidies could actually distort firm size and potentially hurt economic efficiency. A fourth critic view stresses the importance of improving the business environment for all size of firms. Low entry and exit barriers, well defined property rights, and effective contract enforcement characterize a business environment that is conducive to competition and private commercial transactions. While these factors may encourage SMEs, the focus of the business environment view is not on SMEs per se; it is on the environment facing all businesses. Finally, a fifth skeptical view of SME policy (Levine, 2005) argues that these policies are probably most needed where they are less likely to succeed: if SME face institutional obstacles due to some sort of regulatory capture, it is very likely that SME programs will also be captured.

Although this debate is far from reaching any consensus, as a matter of fact many LAC Governments have over time introduced an increasingly complex set of SME policies. Figure 1 summarizes some SME policies applied in Latin America aggregated in terms of the variable they aim to affect. The instruments commonly used by the SME policy are credit, matching grants, technical assistance, and fiscal incentives. One important characteristic of the SME policy is that there are many programs and it is not possible to

\footnotetext{
${ }^{6}$ The emergence of highly competitive clusters and industrial districts - often composed by SMEs or by combinations of large firms and small providers - has introduced new justifications for policies targeted at SMEs. In this case, the local concentration of SMEs specialized in a specific production has been seen as a potentially efficient combination of production scale and flexibility, which, however, requires again important coordination efforts by the firms involved in rather complex production systems. In this case, specific policies have been advocated to support the process through which SMEs identify and finance joint activities aimed at improving the cluster systemic efficiency and at dealing with local externalities (for examples on LAC, see Pietrobelli and Rabellotti 2004).
} 
include all of them in one figure and therefore some countries and policies were selected.

[FIGURE 1 ABOUT HERE]

\section{The relationship between size and productivity}

SME Policy affects the aggregate level of productivity through two channels. First, SME policies can affect aggregate productivity by directly influencing the productivity of SMEs and, thus, the productivity gap between SMEs and large firms. Second, if SME and large firms differ in productivity, SME policies can influence aggregate productivity through the reallocation of resources across SME and large firms.

The empirical framework below decomposes aggregate productivity in a country into these two channels. The framework takes into account that SMEs might be more or less productive than large firms and that aggregate productivity also depends on how resources are allocated between these two groups of firms. Therefore it is thus well suited to examine the importance of SMEs for aggregate productivity through these two channels.

The aggregate level of productivity in period $t, P_{t}$, is given by

$$
P_{t}=\sum_{i=1}^{N} \omega_{i t} P_{i t} \text {, }
$$

where $P_{i t}$ and $\omega_{i t}$ are the market share and the productivity level of firm i in period t. The market share is given by the ratio between firm i's sales $Y_{i t}$ and the total sales $Y_{t}$ defined as the sum of firms's sales in period $t$. For simplicity we are currently performing productivity decomposition for the economy as a whole without focusing on firms' industry affiliation. ${ }^{7}$

We are interested in evaluating the impact of the SME Policy, so we can decompose $P_{t}$ into productivity contribution attributed to SME firms and large firms as follows

$$
P_{t}=\sum_{i \in S M E} \omega_{i t} P_{i t}+\sum_{i \in \text { Large }} \omega_{i t} P_{i t}
$$

This expression can be written as

\footnotetext{
${ }^{7}$ When different industries are considered this should be done by industry and after that the data needs to be weighted by the industry shares. This point is important when working with sample data. In a stratified random sample, all population units are grouped within homogeneous groups and simple random samples are selected within each group. This method allows computing estimates for each of the strata with a specified level of precision while population estimates can also be estimated by properly weighting individual observations.
} 


$$
P_{t}=\frac{Y_{S M E, t}}{Y_{t}} \sum_{i \in S M E} \frac{Y_{i t}}{Y_{S M E, t}} P_{i t}+\frac{Y_{\text {Large }, t}}{Y_{t}} \sum_{i \in \text { Large }} \frac{Y_{i, t}}{Y_{\text {Large }, t}} P_{i t},
$$

then $P_{t}=\omega_{S M E, t} P_{S M E, t}+\omega_{L \text { arge }, t} P_{L \text { arge }, t}$, with $\quad P_{s, t}=\sum_{i \in s} \frac{Y_{i t}}{Y_{s, t}} P_{i t}, \quad \omega_{s, t}=\frac{Y_{s, t}}{Y_{t}} \quad$ and $\quad s=S M E, L$.

Given that $\omega_{S M E, t}+\omega_{\text {Large }, t}=1$,

$$
P_{t}=P_{L \arg e, t}+\omega_{S M E, t}\left(P_{S M E, t}-P_{L \arg e, t}\right)
$$

This expression clearly shows that the level of productivity depends on the level of aggregate productivity of each size group and the contribution to aggregate production of the SME sector. Therefore, changes in the aggregate level of productivity $\left(P_{t}\right)$ can result from changes in the productivity of each size group (i.e., changes in $P_{S M E, t}$ and $P_{L \text { arge }, t}$ ) or changes in the allocation of resources between size groups (i.e., changes in $\omega_{S M E, t}$ ). Policies aiming to support SME may affect both $P_{S M E, t}$ and $\omega_{S M E, t}$.

The impact on aggregate productivity induced by changes in the productivity of each size group is clear: aggregate productivity will be higher if there is an increase in the productivity of the small or large firms. However, an increase in the share of the SME sector will only increase aggregate productivity if SME firms tend to be more productive than large firms. Most of the existing evidence suggests that, on average, large firms have higher total factor productivity. ${ }^{8}$ If SME are less productive than larger firms, policies aiming to increase the proportion of the SME sector (e.g. employment policies) without increasing its productivity may have a negative impact on aggregate productivity.

This framework thus indicates that it is important to consider the reallocation and direct productivity channel when discussion policy options for SMEs. If SME are less productive than larger firms, policies aiming to increase the proportion of the SME sector (e.g. employment policies) without increasing its productivity may have a negative long run impact on aggregate productivity. In this context, aggregate productivity could be at least in principle be improved by SME policies that increase the productivity of the SME sector, $P_{S M E, t}$ and that do not simultaneously reduce productivity of large firms.

\section{Data and Descriptive Statistics}

We use plant level data from The World Bank Enterprise Surveys (WBES). The surveys

\footnotetext{
${ }^{8}$ For example, Söderbom and Teal, 2004 find that SMEs are more productive in Africa, while Van Biesebroeck, 2005, also for Africa, reaches the opposite conclusion; other relevant papers are Alvarez and Crespi, 2003 for Chile; and Diaz and Sanchez, 2008, for Spain.
} 
are applied to a representative sample of firms in the non-agricultural economy and cover plants with more than five employees. The sample includes manufacturing, services, transport, construction sectors. However, only manufactures has been surveyed in all LAC countries and therefore we restrict our analysis to the manufacturing sector. The information for the majority of countries was surveyed in 2006. However, there are some countries with information for 2003 and others with information for 2003 and 2006.

The principal advantage of this dataset is that it provides homogeneous information for sixteen LAC countries. ${ }^{9}$ Surveys are designed in the same way, with similar questionnaire structure and follow similar sampling frames. ${ }^{10}$ This is important advantage with respect to previous studies that present evidence only for a small set of countries.

WBES provides us with the necessary information to estimate Total Factor Productivity (TFP) at the plant level. It also provides information about the firm (ownership, other plants, organization) and some characteristics of the plant (age, etc) and a set of variables that can be modified by SME policy, such as access to credit, training, and process innovation. See Appendix A for the list of variables we were able to match across all the surveys.

The datasets have two limitations. First, all the plants in the dataset belong to formal firms with more than 5 employees. As mentioned in section 2, this is important because in LAC economies a large proportion of employment takes place in micro and informal firms. Unfortunately, there is no dataset covering informal or micro firms for all the considered countries. The second limitation is that the surveys do not provide us with panel data information. The lack of panel data limits our ability to control for the endogeneity of both inputs and productivity determinants.

The log of Total Factor Productivity (TFP) of firm $i$ is given by $p_{i}$

$$
p_{i}=y_{i}-\alpha_{l} l_{i}-\alpha_{m} m_{i}-\alpha_{k} k_{i}
$$

where $y, l, m$, and $k$ are the log value of sales, log number of hours worked per year by temporary and permanent workers, the log value of materials and the log value of capital, respectively. In all the surveys monetary variables are in local currency units (LCUs) and were converted into US dollars.

Because of the lack of panel data, we estimate the input-output elasticities $\left(\alpha_{l}, \alpha_{m}, \alpha_{k}\right)$ by the cost share of each input. ${ }^{11}$ An important assumption behind this estimation procedure is

\footnotetext{
${ }^{9}$ The countries are Argentina (2006), Bolivia (2006), Brazil (2003), Chile (2004, 2006), Colombia (2006), Costa Rica (2005), Ecuador (2006), El Salvador (2003, 2006), Guatemala (2003, 2006), Honduras (2003, 2006), Mexico (2006), Nicaragua (2003, 2006), Panama (2006), Paraguay (2006), Peru (2006), and Uruguay (2006).

10 The sampling frame in 2006 is different than the sampling frame in previous years. In 2006 there was stratified sapling.

11 Alternatively, the input-output elasticities can be obtained by estimating the production function.
} 
the presence of constant returns to scale (CRS) at the industry level. This assumption can be problematic in our case because our objective is to compare the productivity of firms of different size and therefore the scale is the relevant dimension. If the CRS assumption does not hold, the input-output elasticities have to be multiplied by the returns to scale parameter to obtain a measure of productivity.

Under non-CRS, the log of productivity of firm $i$ is given by

$$
p_{i}=y_{i}-\gamma\left[\alpha_{l} l_{i}+\alpha_{m} m_{i}+\alpha_{k} k_{i}\right]
$$

where $\gamma$ is the parameter of the returns to scale. The comparison of productivity between SMEs and large firms is affected by the returns to scale parameter. Suppose for simplicity that $\mathrm{i}=\mathrm{S}$, L (i.e. we only have two firms; one small and one large). The difference in productivity between these two firms is given by

$$
p_{L}-p_{S}=\left(y_{L}-y_{S}\right)-\gamma\left[\alpha_{l}\left(l_{L}-l_{S}\right)+\alpha_{m}\left(m_{L}-m_{S}\right)+\alpha_{k}\left(k_{L}-k_{S}\right)\right] .
$$

When there is increasing returns to scale (IRS) (i.e. $\gamma>1$ ) the assumption of CRS (i.e. $\gamma=1$ ) introduces a bias in favor of large firms. On the other hand, when there is decreasing returns to scale (DRS) (i.e. $\gamma<1$ ) the assumption of CRS introduces a bias in favor of small firms. $^{12}$

\section{The productivity gap between SMEs and large firms}

The economic theory does not provide an answer to the question regarding the relative productivity of SMEs with respect to large firms. On the one hand, large firms may take advantage of economies of scale and scope and more easily undertake some fixed costs. On the other hand, small firms may have higher flexibility to face changes in their environment, they may use cooperation to achieve economies of scale and scope similar to those of larger firms; or they may simply focus on small and highly specialized markets.

In this section we compare the productivity distribution of SMEs with that of large firms. To compare the productivity of firms in different industries in this section we use a productivity index that measures the proportional difference of TFP for firm $i$ relative to a reference firm that varies across industries (Caves, Christensen and Diewert, 1982). For a given industry $j$, the firm of reference is defined as the firm that has: (i) its output is equal

Unfortunately, without panel data information it is difficult to control for the endogeneity of the inputs (See Olley and Pakes, 1996; Levinshon and Petrin, 2003; and Ackerberg et al 2007).

${ }^{12}$ For robustness in the empirical analysis that follows we allowed the scale parameter to vary from 0.8 to 1.2 , and the results did not change significantly. We also estimated the production function ignoring the endogeneity of the inputs. The estimation rejects the CRS assumption in favor of IRS. However, the value of the returns to scale parameter is not far from 1; it lies between 1.03 and 1.05 depending on the industry 
to the geometric mean of firm's output quantities in industry $j$ over the entire period; (ii) the quantities of inputs are equal to the geometric means of firms input quantities in industry $j$ over the entire period; and (iii) the cost shares of inputs are equal to the arithmetic mean of firms cost shares in industry $j$. Therefore, when observations of different industries are pooled, productivity differences among industries are removed. If firm $i$ belongs to the industry $j$, then its productivity index (in logs) is given by

$$
\omega_{i}=\left(y_{i}-\bar{y}_{j}\right)-\sum_{x=\{l, m, k\}} \frac{\alpha_{x, i}+\alpha_{x, j}}{2}\left(x_{i}-\bar{x}_{j}\right),
$$

where $x=l$ (labor), $m$ (materials), $k$ (capital); $j=1,2, \ldots, \mathrm{J}$ (number of industries); and for a generic variable $\mathrm{z}_{i}$ which can be $y_{i}$ (sales), or $\mathrm{x}_{i}$; $\overline{\mathrm{z}}_{j}$ is the average value of $\mathrm{z}$ for the firms in industry $j$. Averages are computed within each country, therefore each country has its own reference firm for each industry.

With the TFP index defined in (7) it is possible to pool all the observations within each country and to compare the productivity distribution of SMEs and the productivity distribution of large firms. Figure 2 shows the cumulative distribution function (cdf) of the productivity index in (7) of SMEs and large firms in selected countries. In Brazil, Mexico, Costa Rica and Panama, the cdf of large firms is at the right of the cdf of small firms indicating stochastic dominance. On the other hand, in Argentina and Bolivia the difference is not clear. Hence, these results indicate that large firms tend to be more productive than SMEs, although the evidence is less clear cut in Argentina and Bolivia.

\section{[FIGURE 2 ABOUT HERE]}

To summarize the information for all countries we use the relative distribution function, R. ${ }^{13}$ This distribution allows us to compare a distribution $\mathrm{G}$ with a reference distribution $\mathrm{F}$. The relative distribution function is defined as $R(r)=G\left(F^{-1}(r)\right)$ where $0 \leq r \leq 1$. If both distributions are identical then $\mathrm{R}(\mathrm{r})$ is the uniform distribution on $[0,1]$. Figure 3 shows the relative distribution function for all the countries.

\section{[FIGURE 3 ABOUT HERE]}

The diagonal represents the uniform distribution, i.e., the relative distribution if both distributions were identical. The position of the relative distribution below the diagonal suggests that the distribution represented in the vertical axis stochastically dominates the distribution in the horizontal axis.

With the exception of Argentina and Bolivia, all the distributions are below the diagonal indicating that the cdf of productivity in large firms stochastically dominates the cdf of

\footnotetext{
${ }^{13}$ This function has been used by Delgado et al (2002) to compare the productivity cdf of exporters and nonexporters.
} 
SMEs. Again, this shows that large firms have higher productivity than small firms, except in Argentina and Bolivia were the results are not that clear.

In light of this productivity gap showed in this section, policies that shift resources toward SME firms (without affecting firms' productivity), might have a negative effect on aggregate productivity because less productive firms would account for a larger share of economic activity.

\section{Understanding the productivity gap}

Is there any room for public policies in increasing the productivity of SME? The best way of answering this crucial question ${ }^{14}$ would be to produce a significant number of studies on the impact of SME policies and their cost effectiveness, which means their effectiveness compared to other policy options. Unfortunately, such a set of studies has not been developed yet, and the rare evaluations that rigorously address this issue do not provide enough critical mass to draw significant conclusions.

While policy makers, scholars and international agencies should drastically increase the resources devoted to impact evaluations of SME policies, other approaches should also be explored to have at least a glimpse on the adequacy of the SME policies. This section and the following are an attempt of doing that. We decompose the productivity gap in its major determinants, with particular attention to the variables usually targeted by SME policies, for instance access to credit, innovation, training and quality certification. Once the determinants of the productivity gap have been indentified and the relevance of the factors targeted by SME-policies has been tested, we simulate what would be the impact of expanding these policies on the productivity level.

To study how the variables that can be affected by SME Policy affect productivity, we consider two procedures: (i) a linear regression model, and (ii) quasi-experimental techniques.

In the first procedure we directly address the question of how much of the productivity gap can be explained by variables that can be affected by SME Policy. Let $p_{i}$ be the productivity of firm i defined in (4), $S_{i}$ a set of size dummies, $X_{i}$ a set of variables that can be affected by SME policy, $Z_{i}$ a set of exogenous control variables, and $C_{i} \times Y_{i}$ and $I_{i}$ a set of country-year and industry dummies. We run two regressions; one restricting the coefficient of the variables in $X_{i}$ to zero and other without any restriction. In these models we compare the coefficients of the size dummies and the difference in productivity by size category that can explain each model. The regressions are the following

\footnotetext{
${ }^{14}$ Crucial because of the increasing amount of resources devoted to SME policies.
} 


$$
\begin{gathered}
p_{i}=c_{r}+\alpha_{s, r}^{\prime} S_{i}+\alpha_{z, r}^{\prime} Z_{i}+\alpha_{c, r}^{\prime} C_{i} \times Y_{i}+\alpha_{I, r}^{\prime} I_{i}+\varepsilon_{r i} \\
p_{i}=c_{u}+\alpha_{s, u}^{\prime} S_{i}+\alpha_{x, u}^{\prime} X_{i}+\alpha_{z, u}^{\prime} Z_{i}+\alpha_{c, r}^{\prime} C_{i} \times Y_{i}+\alpha_{I, r}^{\prime} I_{i}+\varepsilon_{u i}
\end{gathered}
$$

The variables that we include as policy variables (variables that can be affected by SME policy) are training, credit, product innovation, ISO certification. The definition of these variables is as follows: (i) Training is a dummy variable that takes value one if the firm offers training to their employees, (ii) Credit is a dummy variable that takes value one if the firm reports that it has a credit line or overdraft facilities, (iii) Product innovation is a dummy variable that takes value one if the firm reported a product innovation in the last three years, (iv) ISO certification is a dummy variable that takes value one if the firm has ISO certification.

These variables may result endogenous. Training is endogenous because it is likely that more productive firms offer training to their employees because they may be in a better financial position to do that. In the same way, credit is endogenous because it is possible to think that more productive firms are those that receive credit from financial institutions.

To deal with the endogeneity of these variables we apply instrumental variables. We first consider as instrument the proportion of firms reporting training, credit, product innovation, and ISO certification in two clusters of firms: (i) firms in the same country and industry and, (ii) firms in the same industry and size category. That is, i.e., for each endogenous variable we consider two instruments. After testing the validity of those instruments, we consider adding as additional instruments the proportion of firms reporting training, credit, product innovation, and ISO certification in a cluster of firms in the same country, industry and size category. We test the validity of this extra set of instruments using the incremental Sargan test. The use of IV methods is warranted given the cross-section nature of the data; however the difficulty of finding appropriate instruments in this data calls for caution in the interpretation of results.

With the set of variables in $Z_{i}$ we control for: (i) the age of the firm, (ii) the organizational form of the firm -we include dummies for incorporated companies, firms with only one establishment, and firms with only one proprietary, (iii) the level of unionization in the industry and size, (iv) the business cycle -we use the average at the country-industry level of the capacity utilization, and (v) the level of formality of the firm -we include an average at the country-industry-size level of the manager's time dealing with bureaucracy.

With respect to the business cycle we expect a positive relationship because the literature has found that productivity is pro-cyclical. We average across country-industry to capture the business cycle and avoid considering inefficiencies by firm.

We define the level of formality as the manager's time dealing with bureaucracy because it is sensible to expect that the more formal the firm is the more time the manager needs to allocate in dealing with bureaucracy. We take the average across country-industry-size to avoid confusions with efficiency in dealing with bureaucracy at the firm level. 
Table 2 shows the result of the estimation of equations (6.1) and (6.2). We did two different exercises with different definitions of size. First, we consider three size categories -with large firms being the excluded group. Table 2 shows the results as Discrete Size. Second, we consider the number of employees -Continuous Size in Table $2 .^{15}$ In both cases, we estimated (6.2) by OLS and 2SLS.

\section{[TABLE 2 ABOUT HERE]}

Table 2 shows a large gap in productivity between SMEs and large firms. On average, small firms are $22 \%$ less productive than large firms and medium-sized firms are $15 \%$ less productive than large firms. When the regression includes the variables in $X_{i}$ the estimated coefficient on size -both in the discrete and continuous case- is lower. In the OLS columns the estimated coefficients on the size variables are lower but continue to be significant. The magnitudes of the coefficients on size in the 2SLS regressions are substantially lower and no longer statistically significant.

With respect to the variables that can be affected by SME Policy, access to credit, training and ISO certification show positive and significant coefficients. On the other hand, product innovation shows no significant coefficients when estimating by OLS and positive and significant coefficient only in the 2SLS estimation. This non robust result of product innovation can be reflecting the fact that the innovation needs time to produce an increase in productivity.

Table 2 also shows other interesting results. First, more formal firms are more productive. Second, firms with a larger the proportion of unionized workers have lower productivity. Third, the sign of the rest of variables is as expected; productivity is pro-cyclical, older firms are more productive, incorporated companies are more productive and one establishment and one proprietary firm are less productive.

What is interesting to note is that the difference in productivity is present even when the coefficient of size is smaller. Given that the coefficient of the policy variables is the same for small, medium-sized and large firms, the difference in productivity across size is explained by the difference in the variables that can be affected by SME policy. Figure 4 shows the average productivity by size category obtained by the predicted values of equations (6.1) and (6.2) and the average by size of the variables that can be affected by SME policy.

\section{[FIGURE 4 ABOUT HERE]}

As mentioned above, both OLS and 2SLS results go in the same direction in the sense that when including policy variables there is a reduction in the size coefficients. However, the difference between the OLS and 2SLS coefficients is large. When estimating by 2SLS, the

\footnotetext{
${ }^{15}$ We also considered the number of employees the plant had three years before. By considering the size the plant had three years before, we avoid the possible endogeneity that can appear if most productive firms are those that grow and increase their size. Results were robust.
} 
coefficients of the size variables become statistically insignificant and the magnitudes of the estimated coefficients on policy variables increase considerably. However, even when the instruments pass the statistical tests for being considered good instruments, the way in which they have been constructed may cast doubts on the 2SLS estimates and the endogeneity of the policy variables on the OLS results.

Given the inherent problems with OLS and 2SLS, we propose another exercise to obtain the impact of the variables that can be affected by SME policy on plant's productivity. For each one of those variables we evaluate their impact on productivity applying standard methods proposed in the treatment effect literature.

The starting point is the estimation of the treatment effect, which for each participant is defined as

$$
\alpha_{i}=Y_{1 i}-Y_{0 i}
$$

In other words, the impact is the difference in the outcome $(\mathrm{Y})$ depending on whether the firm participated in the program $\left(Y_{1 i}\right)$ or did not participate $\left(Y_{0 i}\right)$. In our case participation means, depending on the case, providing training, having access to credit, having ISO certification, or innovating.

The fundamental problem of evaluation is that, for any given individual $i$, it is impossible to observe both $Y_{1 i}$ and $Y_{0 i}$ simultaneously. For participants, we are interested in $\alpha_{i}=\left(Y_{1 i}-Y_{0 i} \mid T_{i}=1\right)$, but for them it is impossible to observe $\left(Y_{0 i}\right)$.

For the population of beneficiaries we are interested in the average impact of the program $G=E\left(Y_{1 i}-Y_{0 i} \mid T_{i}=1\right)=E\left(Y_{1 i} \mid T_{i}=1\right)-E\left(Y_{0 i} \mid T_{i}=1\right)$, and we need to estimate $E\left(Y_{0 i} \mid T_{i}=1\right)$, the counterfactual of what would the productivity be if the plant that, for example, offer training to their employees would not has offered such a training. The general approach is to approximate $E\left(Y_{0 i} \mid T_{i}=1\right)$ with $E\left(Y_{0 i} \mid T_{i}=0\right)$ using a comparison group, which is formed by plants similar to the one that offered training that did not offered training -and the same for the rest of variables.

The impact evaluation must rest on an adequate and rigorous strategy for identifying a statistically robust control group of non-beneficiaries. A central issue is how to create a valid comparison group, in the sense that the differences in the productivity between participants and non-participants are explained by the program and not by other characteristics. The ideal solution is to have the treatment randomly assigned, in order to guarantee that on average the characteristics of both groups are the same. In the absence of this solution, we aim at identifying individuals that have the same observable relevant characteristics as the participants through matching methodologies. This assumes that the selection of firms into the treatment occurs only through observables, and there is no systematic sorting into treatment based on unobservable firm characteristics.

The procedure is as follows: First, we estimate the probability of participation, 
$\hat{p}\left(S_{i}, Z_{1 i}, C_{i} \times Y_{i}, I_{i}\right)$, by estimating the propensity score

$$
P\left(T_{i}=1 \mid S_{i}, Z_{1 i}, C_{i} \times Y_{i}, I_{i}\right)=\Phi\left(\alpha_{s}^{\prime} S_{i}+\alpha_{z}^{\prime} Z_{1 i}+\alpha_{C}^{\prime} C_{i} \times Y_{i}+\alpha_{I}^{\prime} I_{i}\right)
$$

the variables in vectors $S_{i}, C_{i} \times Y_{i}$, and $I_{i}$ have been defined previously defined. The vector $Z_{1 i}$ is a subset of $Z_{i}$. Summarizing, the observable characteristics we consider are age, the organizational form of the firm (incorporated companies, firms with only one establishment, and firms with only one proprietary), industry, and country-year.

The propensity score is computed for all individuals, those that participated and those that did not participate. The next step involves using matching techniques to compare the productivity of each participant with the productivity of nonparticipants that have similar probability of participation. The general form of the matching estimator is:

$$
\Delta^{M}=\frac{1}{n_{1}} \sum_{i \in\left\{T_{i}=1\right\}}\left[Y_{1 i}-\sum_{j \in\left\{T_{j}=0\right\}} w(i, j) Y_{0 j}\right]
$$

where $n_{1}$ is the number of treated and $w(i, j)$ represents the weight given to the jth observation when constructing the counterfactual for the ith treated observation.

Table 3 shows the results for each of the variables that can be affected by SME Policy for all the firms and considering separately SMEs and large firms.

\section{[TABLE 3 ABOUT HERE]}

The results not only show a consistent and robust relationship between access to credit, training and quality certification and productivity, but also that the relevance of the policy variables is higher in the case of SMEs than larger firms (except in access to credit). It is interesting to note that the magnitude of the impact lies between the one obtained by OLS and 2SLS in Table 2.

In sum, the regression analysis above suggests that smaller and medium sized firms are on average less productive than larger firms. This confirms the finding of the productivity gap between large and small firms in section 5 . Further analysis suggests that the productivity differences between SMEs and larger firms could be in part driven by differential participation of these firms in worker training, credit availability, product innovation and ISO certification; all variables that in principle can be affected by SME Policy. Given the lack panel data, it is difficult to rule out the possibility that the positive association between training, credit availability, etc. and productivity does not simply reflect selection of inherently better firms into these programs or reverse causality, whereby more productive firms have easier access to credit or can afford worker training. If self-selection or reverse causality drives the positive association between training and productivity, then providing SME firms with access to credit or training might not necessarily lead to productivity improvements in SME firms. We attempt to address these concerns by using 2SLS and 
propensity score matching and continue to find support for the above results. Nonetheless, given the structure of our data and strong identification assumption behind these techniques the concerns about the interpretation of results continue to exist.

Do these results imply that SME policies are justified? Even taking the results at face value, one should not jump to the conclusion that SME policies aimed at improving access to credit, promoting training, innovation, and increasing quality certification would necessarily have a positive effect on the overall productivity level, as it is not evident that policies would actually induce the beneficiary firms to engage in those activities that have a positive relationship with productivity - for instance it may be that firms that participate in a training program would have trained their workers anyway with their own resources. Also, the type of activities promoted with public policies is not necessarily the same type as those that implemented by firms on their own - for instance the training provided by SME programs may differ substantially from the training provided by the most productive firms.

\section{The effect of SME Policy via simulations}

In this section we combine the methods used in previous section to simulate the effect of several policies on firms's productivity. We use the reduced form estimates to evaluate the impact of changes in access to credit, training, product innovation and ISO certification on firms's productivity and the propensity score to select the firms that will be receiving the policy, i.e., we use the propensity score as a targeting rule. With the targeting rule we aim at promoting those activities among firms that have not yet implemented them, but that have similar observable characteristics to the ones that have.

We are interested in two questions: (i) How much of the productivity gap can be closed by an SME policy? and (ii) Which is the effect on the aggregate level of productivity?

\subsection{The effect on the productivity gap}

We compare two policy designs:

(i) SME Policy 1: SME Policy targets those SMEs that are not training their workers but have a propensity score higher than 0.5 . We do the same for credit, product innovation, and ISO certification.

(ii) SME Policy 2: SME Policy targets those SMEs that have the highest propensity score of training and are not offering training. In this case, we select firms according their propensity score up to the point where the fraction of SMEs that engage in training is similar to the fraction of large firms that train. We do the same for credit, product innovation, and ISO certification.

To obtain the productivity level of firm $i$ in the baseline, $p_{i}^{B L}$, and under policy $S P, p_{i}^{S P}$, (with $S P=$ training, credit, product innovation, and ISO certification) we use equation (6.2). 
Then, the productivity of firm $i$ in the baseline is

$$
p_{i}^{B L}=\hat{c}_{u}+\hat{\alpha}_{s, u}^{\prime} S_{i}+\hat{\alpha}_{x, u}^{\prime} X_{i}+\hat{\alpha}_{z, u}^{\prime} Z_{i}+\hat{\alpha}_{c, r}^{\prime} C_{i} \times Y_{i}+\hat{\alpha}_{I, r}^{\prime} I_{i}
$$

and under policy SP is

$$
p_{i}^{S P}=\hat{c}_{u}+\hat{\alpha}_{s, u}^{\prime} S_{i}+\hat{\alpha}_{x, u}^{\prime} X_{i}^{S P}+\hat{\alpha}_{z, u}^{\prime} Z_{i}+\hat{\alpha}_{c, r}^{\prime} C_{i} \times Y_{i}+\hat{\alpha}_{I, r}^{\prime} I_{i}
$$

where $X_{i}^{S P}$ is the vector corresponding to the simulated policy.

In our case, all the variables that can be affected by SME Policy are dummy variables and therefore the simulation is computationally simple; it just implies changing zeros by ones in the "policy variables" for those firms receiving the policy. As mentioned above, the rule for assigning the policy is important. Not all the firms the firms that do not offer training to their employees (or are not innovating, etc) receive the policy in the simulation exercise; only those firms that satisfies the conditions described above. Therefore, $X_{i}^{S P}$ is equal to $X_{i}$ except for those firms that were selected to participate in the policy. We do the exercise policy by policy and therefore $X_{i}^{S P}$ differs from $X_{i}$ only in the activity considered by the policy.

Figure 5 shows the distribution of productivity of SMEs and large firms under both scenarios.

\section{[FIGURE 5 ABOVE HERE]}

\subsection{The effect on the aggregate level of productivity}

In order to address the skeptic view that productivity policies should not be targeted exclusively or primarily to SMEs we consider how the aggregate level of productivity would increase under two scenarios: one in which policy is targeted by size (SME Policy) and other one with non-targeted by size policy. The simulated policy designs are as follows

(i) SME Policy 1 of previous subsection.

(ii) Non-Targeted by Size: Policy targets firms with the highest propensity score of training and not currently offering training. We select firms up to the point were the number of firms starting to train their workers is equal to the number of firms starting to train their workers in policy design (i). The same for credit, innovation, and ISO certification.

Let $p_{i}^{B L}$ and $w_{i}^{B L}$ be the productivity and the output-share of firm $\mathrm{i}$ in the baseline. Then the baseline aggregate level of productivity is given by 


$$
P^{B L}=\sum_{i} w_{i}^{B L} p_{i}^{B L}
$$

Let $p_{i}^{S P}$ and $w_{i}^{S P}$ be the productivity and output share of firm $i$ in the simulated policy design $S P$, with $S P$ being training, credit, product innovation and ISO certification. Then the change in the aggregate level of productivity due to policy SP can be decomposed following Foster et al (1998) as follows:

$$
\Delta P^{S P}=\sum_{i} w_{i}^{B L} \Delta p_{i}+\sum_{i}\left(p_{i}^{B L}-P^{B L}\right) \Delta w_{i}+\sum_{i} \Delta w_{i} \Delta p_{i}
$$

where $\Delta p_{i}=p_{i}^{S P}-p_{i}^{B L}$ and $\Delta w_{i}=w_{i}^{S P}-w_{i}^{B L}$.

The first term is the increase in aggregate productivity when firms increase their productivity at baseline market share (the within-plant term). The second term is the increase in productivity resulting when plants with above-average productivity expand their market share relative to plants with below-average productivity (the between-plant term). The third term is the cross-plant term.

The productivity level of firm $i$ in the baseline and under policy SP are defined above. To obtain the change in market shares we use the production function. ${ }^{16}$ Then the value of output and market shares after policy SP are given by ${ }^{17}$

$$
\begin{aligned}
& Y_{i}^{S P}=\exp \left(p_{i}^{S P}\right) L^{\alpha_{l}} M^{\alpha_{m}} K^{\alpha_{k}}, \\
& w_{i}^{S P}=\frac{Y_{i}^{S P}}{\sum_{i} Y_{i}^{S P}}
\end{aligned}
$$

Table 4 shows the results of this simulation. The results show that properly targeted SME policies might have a significant positive effect on aggregate productivity - in the sample adopted for the simulation, they would induce a 5.7 percent aggregate productivity increase (when all policies are performed simultaneously). The overall effect on aggregate productivity is mostly due to the "between-firms" term, which accounts for 65 percent of the aggregate productivity increase, while the "within-firm" term accounts for 45 percent aggregate productivity increase.

\footnotetext{
${ }^{16}$ Similar approach was proposed by Escribano et al (2008) to obtain the market shares in a simulation on the impact of the investment climate on the components of the Olley and Pakes decomposition.

${ }^{17}$ We are considering only the direct change in output due to changes in productivity. The input demand functions are also function of productivity and therefore the output is also affected by changes in inputs induced by the productivity change. For simplicity, we are ignoring those changes.
} 
[TABLE 5 ABOUT HERE]

In the case of Non-Targeted by Size Policy, the simulation shows that the overall impact on aggregate productivity would be much higher than in the previous case, with a 10.5 percent overall impact on aggregate productivity. The decomposition of this effect is also quite different that in the previous case. In fact, most of the impact on productivity is due to the "within-firms" term, which accounts for 81 percent of the increase. This is clearly due to the fact that non-SME-targeted policies would affect the productivity of firms with larger initial market share, increasing the importance of the contribution of the "within-effect".

\section{Evidence on the effectiveness of SME Policy from impact evaluations}

As mention before, a large set of rigorous impact evaluations would be extremely beneficial for previous discussion on the effect of SME policies on aggregate productivity. Unfortunately, in Latin America and the Caribbean SME policies have not been properly evaluated. Most policies are not even properly monitored, and a rigorous analysis of their results in terms of fostering the growth and productivity of SMEs is missing. Although large sums of resources are invested in SME policies ${ }^{18}$, the information of the results of these policies is nil. A recent overview of SME policies in Peru, for example, shows that of the eighteen most important programs, only one has a monitoring and evaluation component (although a rigorous evaluation has not taken place). The same study (Diaz and Jaramillo, 2009) reports that SME policies in Peru are characterized by being spread too thin: policies and programs exist to work on a wide range of issues related to SMEs. However another characteristic is that these policies lack a diagnosis that would allow them to solve specific problems faced by SMEs, and the third feature is that the coverage of SME policies is extremely low.

In Mexico, since 2000 Congress required annual evaluations of all public projects managed by the federal government and that involved subsidies or transfers. Hence, many SME projects have been in principle evaluated. However, the quality of those evaluations is very low. A review of the most recent set of evaluations of SME projects show that in most of them, the monitoring and evaluation systems are not designed to gather information on results. ${ }^{19}$ In 2007, The World Bank published a study on the evaluation of SME policies in

\footnotetext{
${ }^{18}$ In Mexico, for example, there are more than 140 programs that have as one of their objective to work with SMEs. The approximate resources spent in the largest twenty five of them is about US\$3 billion (see Soto, 2009), a figure similar to what the government spends in the CCT Oportunidades, that reaches 5 million families.

19 See the process evaluations (Evaluación de Consistencia y Resultados) of 2007 of the National Evaluation Council (CONEVAL, www.coneval.gob.mx)
} 
Mexico, and reported that only one program have had impact evaluations using comparison groups and looking at intermediate and ultimate objectives The results of those impact evaluations suggest "that SME programs influence intermediate outcomes, including training and technology adoption... the measurement of positive program impacts on final outcomes [improved performance, productivity, wages and export orientation] remains elusive." 20 The conclusions of the study for Mexico are similar than those posed for Chile by Goldberg and Palladini (2008), in that a comprehensive system to monitor and evaluate these programs is required.

In Colombia, the shortage of impact evaluations of programs that support SME is also apparent. One exception is the evaluation of job training programs administered by SENA, which were evaluated by Barrera and Corchuelo (2004) on the basis of the impact on workers compensation and not firm productivity, showing a positive effect on workers compensation. More recently, an impact evaluation of FOMIPYME, the main program to support the development of SME in the country, showed mixed results. According to the evaluation, DNP (2008), the program had some positive impacts on employment and sales, but no impact on productivity. However, the same document notes that the lack of a baseline and important data limitations are important caveats to interpreting the results of the evaluation as definitive. In terms of export promotion, Volpe and Carballo (2008) find a positive impact of export promotion programs on export diversification, though presenting no results on productivity.

In Argentina, the evaluation work has been focused on innovation programs. Binelli and Maffioli (2006) evaluate the PMT (Programa de Modernización Tecnológica), which provided matching grants to firms for the implementation of innovative practices. Results show important heterogeneity of impact, with more established firms, on average, using grants to displace innovation that they were already planning to undertake, whereas startup firms use the grants to finance innovation they otherwise would not have been able to undertake, generating an impact on innovation only on smaller firms.

Hall and Maffioli (2008) present a survey of the evaluations of government Technology Development Funds (TDF) in Argentina, Brazil, Chile and Panama. Four levels of potential impact were considered: (i) R\&D input additionality, (ii) behavioural additionality, (iii) increases in innovative output, and (iv) improvements in performance. The evidence reported suggests that TDF do not crowd out private investment and that they positively affect R\&D intensity. In addition, participation in TDF induces a more proactive attitude of beneficiary firms towards innovation activities. However, the analysis does not find much statistically significant impact on patents or new product sales and the evidence on firm performance is mixed, with positive results in terms of firm growth, but little corresponding positive impact on measures of firm productivity. This can be the result of the short horizon over which the evaluation was conducted. ${ }^{21}$

\footnotetext{
${ }^{20}$ See World Bank, 2007. Also for Mexico, see OECD (2007) and Storey (2008) for a review the evaluation of SME support programs in Mexico.

${ }^{21}$ Other papers on the evaluation of Science and Technology Programs are Binelli and Maffioli (2007) and
} 
Looking to other developing countries outside LAC, there have been illustrative experiences on SME training programs, particularly in South Korea. In that country, several models of financial incentives to firms to promote training were implemented without success. However, when SMEs were given institutional and technical assistance the results were positive, both in terms of the involvement of firms and on the productivity of firms. This experience also documents the need for an integrated SME policy, not only in terms of instruments (technical assistance, subsidies) but also in terms of working with groups of SMEs and in alignment with business organizations. ${ }^{22}$

\section{Concluding Remarks}

Do SME policies improve productivity in Latin America and the Caribbean? Sadly, the enormous enthusiasm that governments and international agencies have shown towards financing SME policies and promoting the growth and development of the SME sector has not been accompanied by a similar eagerness to track the results and measure the impacts of such policies. This worrisome reality is not limited to the productivity dimension: overall it is not clear if firms that have benefited from SME programs have in fact survived more or generated more employment than what would have taken place in the absence of such programs. Hence, it is unknown whether SME policies contribute to productivity.

Can SME policies improve productivity in Latin America and the Caribbean? In principle yes, if they are properly targeted and they are able to foster training, innovation, certification and access to credit, i.e. those factors that seem to explain the productivity gap with larger firms. However, even setting aside crucial issues related to the costs and implementation of these policies, expectations should be realistic in that the potential for productivity growth through SME policies is limited and could be lower than the effect of the same policies not specifically targeted at SMEs, but applied to all firms.

\section{References}

Acs, Z. and L. Szerb (2006): "Entrepreneurship, Economic Growth and Public Policy," Small Business Economics, 28, 109-122.

Acs, Z. and P. Mueller (2008): "Employment Effects of Business Dynamics: Mice, Gazelles and Elephants,” Small Business Economics, 30, 85-100.

Benavente, Crespi and Maffioli (2007).

${ }^{22}$ See Lee (2006). This comprehensive approach was successfully implemented in Mexico (but it was later abandoned) and has been tried in other countries like Panama. 
Alvarez, R. and G. Crespi (2003): "Determinants of Technical Efficiency in Small firms," Small Business Economics, 20, 233-244.

Angelelli, P., R. Moudry, and J. Llisterri (2006): "Institutional capacities for Small Business Policy Development in Latin American and the Caribbean.” InterAmerican Development Bank. Sustainable Development Department. Technical Paper Series, MSM-136.

Ayyagari, M., T. Beck, and A. Demirguc-Kunt (2007): "Small and Medium Enterprises across the Globe,” Small Business Economics, 29, 415-434.

Baily, M. and R. Solow (2001): "International Productivity Comparisons Built from the Firm Level,” Journal of Economic Perspectives, 15(3), 151-172.

Beck, T., A. Demirguc-Kunt and R. Levine (2005): "SMEs, Growth, and Poverty: CrossCountry Evidence,” Journal of Economic Growth, 10, 199-229.

Benavente, J. and G. Crespi (2003): "The Impact of an Associative Strategy (the PROFO Program) on Small and Medium Enterprises in Chile,” SPRU Electronic Working Paper Series 88, University of Sussex, SPRU - Science and Technology Policy Research

Benavente, J., Crespi, G. and Maffioli, A. (2007a): "The Impact of National Research Funds: An Evaluation of the Chilean FONDECYT,” OVE Working Papers 0307, Inter-American Development Bank, Office of Evaluation and Oversight (OVE).

Benavente, J., Crespi, G. and Maffioli, A. (2007b): "Public Support to Firm-Level Innovation: An Evaluation of the FONTEC Program,” OVE Working Papers 0507, Inter-American Development Bank, Office of Evaluation and Oversight (OVE).

Benelli, C. and A. Maffioli (2007): "A microeconometric analysis of Public Support to R\&D in Argentina,” International Review of Applied Economics, 21(3), 339-359.

Canales Salas, D., L. Madrigal Correa, A. Saracho Martínez and C. Valdés Galicia (2008): "El Tamaño Importa: Las políticas pro PYMES y la competitividad," Fundación para la implementación, Diseño, Evaluación y Análisis de Políticas Públicas, Fundación IDEA.

Caves, D., L. Christensen, and E. Diewert (1982): "Multilateral Comparisons of Output, Input and Productivity Using Superlative Index Numbers,” Economic Journal, 92 (365), 73-86.

Cerdán-Infantes, P., Maffioli, A., Ubfal, D. (2008): “The Impact of Agricultural Extension Services: The Case of Grape Production in Argentina," OVE Working Papers 0508, Inter-American Development Bank, Office of Evaluation and Oversight (OVE).

Cole, H., L. Ohanian, A. Riascos and J. Schmitz Jr. (2005): "Latin America in the Rearview Mirror,” Journal of Monetary Economics, 52(1), 69-107. 
Delgado, M, J. Fariñas, and S. Ruano (2002): "Firm productivity and export markets: A nonparametric approach,” Journal of International Economics 57, 395-422.

Escribano, A., L. Guasch, M. Orte, and J. Pena (2008): “Investment Climate Assessment Based on Demean Olley and Pakes Decompositions: Methodology and Application to Turkey's Investment Climate Survey,” Working Paper 08-20, Department of Economics, Universidad Carlos III de Madrid.

Foster, L., J. Haltiwanger and C. J. Krizan (2001): "Aggregate Productivity Growth: Lessons from Microeconomic Evidence,” In New Developments in Productivity Analysis, ed. E. Dean, M. Harper, and C. Hulten, 303-363. Chicago, University of Chicago Press.

Foster, L., J. Haltiwanger and C. J. Krizan (2006): "Market Selection, Reallocation, and Restructuring in the U.S. Retail Trade Sector in the 1990s," The Review of Economics and Statistics, 88(4), 748-758.

Foster, L., J. Haltiwanger and C. Syverson (2008): "Reallocation, Firm Turnover, and Efficiency: Selection on Productivity or Profitability?” American Economic Review, 98(1), 394-425.

Goldberg, M. and E. Palladini (2008): “Chile: A Strategy to Promote Innovative Small and Medium Enterprises,” The World Bank, Policy Research Working Paper 4518.

Hall, B. and A. Maffioli (2008): "Evaluating the Impact of Technology Development Funds in Emerging Economies: Evidence from Latin America," OVE Working Papers 0108, Inter-American Development Bank, Office of Evaluation and Oversight (OVE).

Maffioli, A. (2003): "SME Competitiveness in Latin America: The role of university driven networks,” ISLA Bocconi WP, 15-LA, Milan, 2003.

Maffioli, A. (2005): “The Formation of Network and Public Intervention: Theory and Evidence from the Chilean Experience," ISLA Working Papers 23, ISLA, Centre for research on Latin American Studies and Transition Economies, Universita' Bocconi.

OECD (2005): “OECD SME and Entrepreneurship Outlook 2005.” OECD.

OECD (2007): “SMEs in Mexico: Issues and Policies.” OECD.

Olley, G. S. and A. Pakes (1996): "The Dynamics of Productivity in the Telecommunications Equipment Industry,” Econometrica 64(6), 1263-1297.

Peres, W. and G. Stumpo (2000): "Small and Medium-Sized Manufacturing Enterprises in Latin America and the Caribbean Under the New Economic Model," World Development, 28(9),1643-1655. 
Storey, D. J. (2008): “Entrepreneurship and SME policy in Mexico,” mimeo.

United Nations (2003): "Small and Medium-Sized Enterprises in Countries in Trasition," United Nations Economic Commission for Europe, Series Entrepreneurships and SMEs.

You, J. (1995): “Small Firms in Economic Theory,” Cambridge Journal of Economics 19, 441-462. 


\section{Appendix A: Variable Definitions}

Sales: Value of sales reported by firms. Local currency units (LCUs) were converted to USD using data on exchange rates from IMF.

Employment: Total number of permanent and temporary workers. The number of temporary workers is weighted by the average length of employment of temporary workers. Only LAC countries have information on the length of employment of temporary workers

\section{Total hours worked per year:}

Labor cost: Labor cost reported by firms. Local currency units (LCUs) were converted to USD using data on exchange rates from IMF.

Material cost: Cost of materials excluding fuel reported by firms. Local currency units (LCUs) were converted to USD using data on exchange rates from IMF.

Capital Stock: Book value of all fixed assets (excluding land). Local currency units (LCUs) were converted to USD using data on exchange rates from IMF.

User cost of capital: It is assumed to be $15 \%$ of the capital stock.

Age: Age of the firm.

Listed company: Dummy that takes value one if the legal status of the company is listed company.

Sole proprietorship: Dummy that takes value one if the legal status of the company is sole proprietorship.

Partnership: Dummy that takes value one if the legal status of the company is partnership.

One establishment: Dummy that takes value one if the firm has only one establishment.

Foreign direct investment: Percentage of foreign capital.

Direct exports: Percentage of sales exported directly.

Indirect exports: Percentage of sales exported indirectly.

Exporting experience: Number of years since the firm exported for the first time.

Use email: Dummy that takes value one if the firm uses email with its clients and suppliers.

Use website: Dummy that takes value one if the firm uses a website with its clients and suppliers. 
Manager in bureaucratic issues: Percentage of senior management time in bureaucracy. The question in the questionnaire is "In a typical week, what percentage of senior management's time is spent in dealing with requirements imposed by government regulations (e.g. taxes, customs, labor regulations, licensing and registration) including dealing with officials, completing forms, etc.)

Credit line: Dummy that takes value one if the establishment has an overdraft facility or credit line.

No competitors: Dummy that takes value one if the firm has no competitors.

Between one and five competitors: Dummy that takes value one if the firm has between one and five competitors.

More than five competitors: Dummy that takes value one if the firm has more than five competitors.

Capacity utilization: Is the amount of output actually produced relative to the maximum amount that could be produced with the existing machinery and equipment and regular shifts. It is the average value over the year.

Use Licensed technology: Dummy establishment uses technology licensed form a foreign owned company.

Product innovation: Dummy in the last three years product innovation.

Process innovation: Dummy in the last three years process innovation.

ISO certification: Dummy firm has ISO certification.

Skilled workers: Percentage of permanent workers that is skilled.

Non-production workers: Percentage of permanent workers that is non-production.

Training: Dummy the establishment offer training to its permanent workers.

Unionized workers: Percentage of workforce unionized. 
Distribution of programs by country (\%)

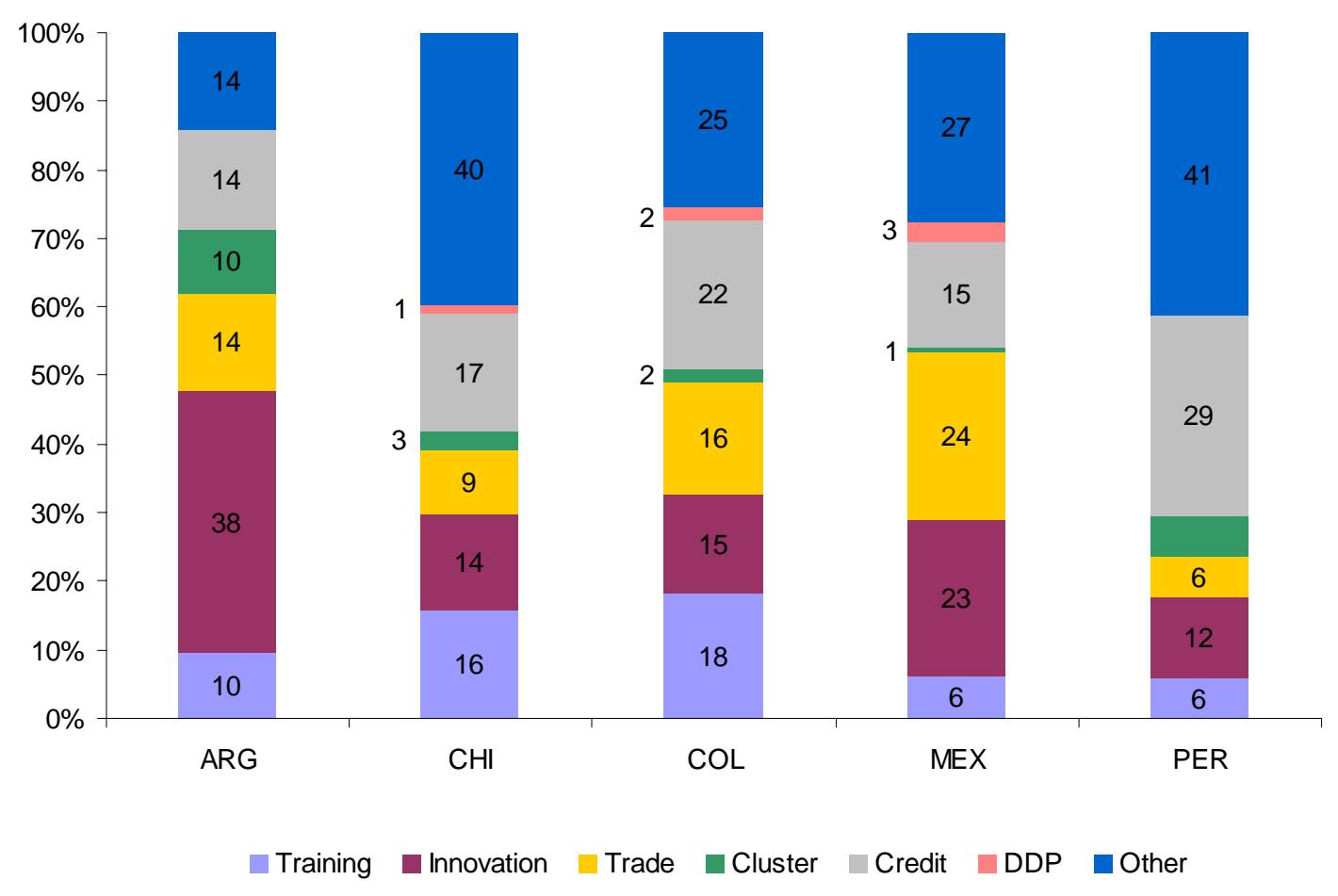

Figure 1: SME Policy in several LAC countries 

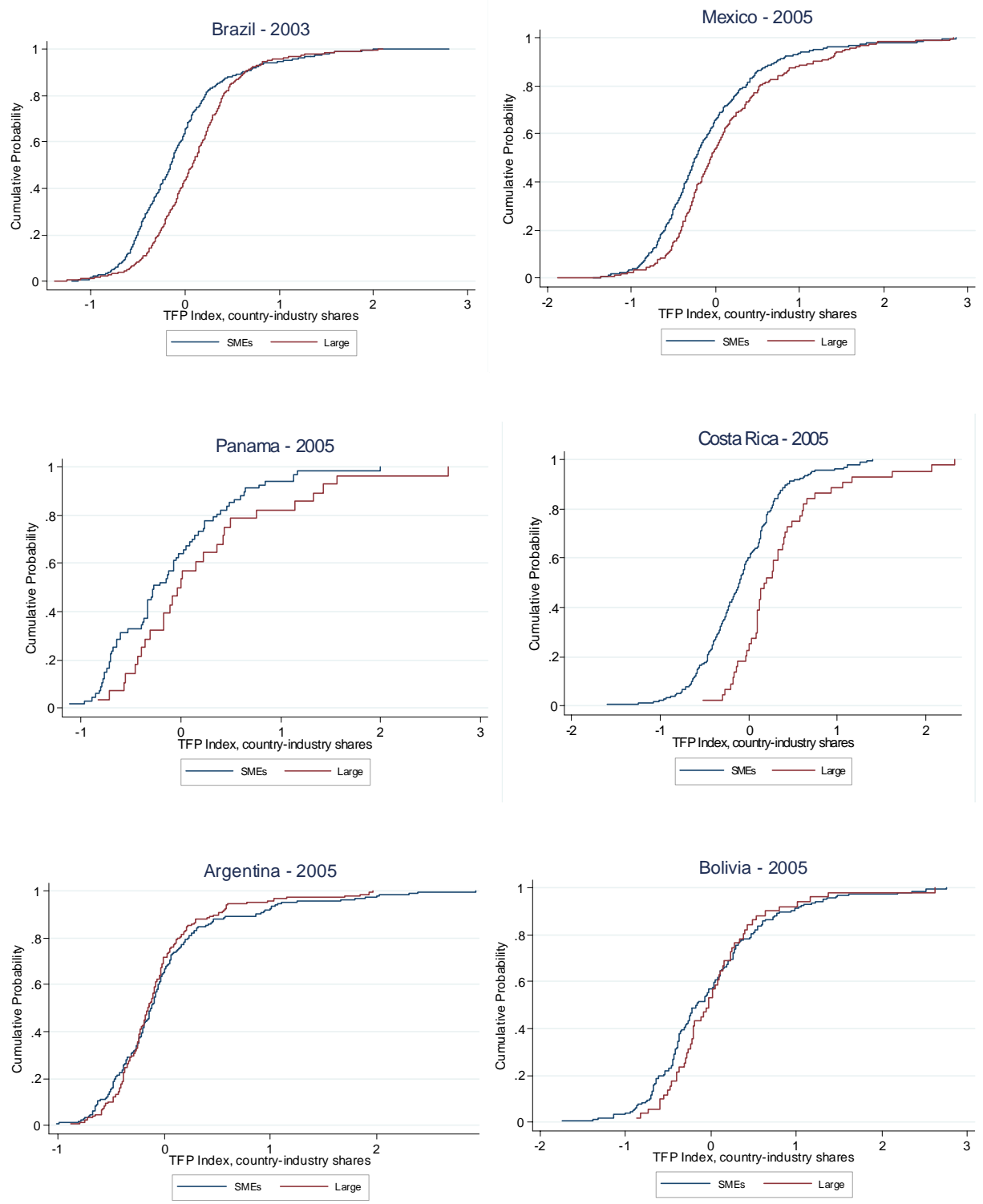

Figure 2: The productivity gap: Selected countries 


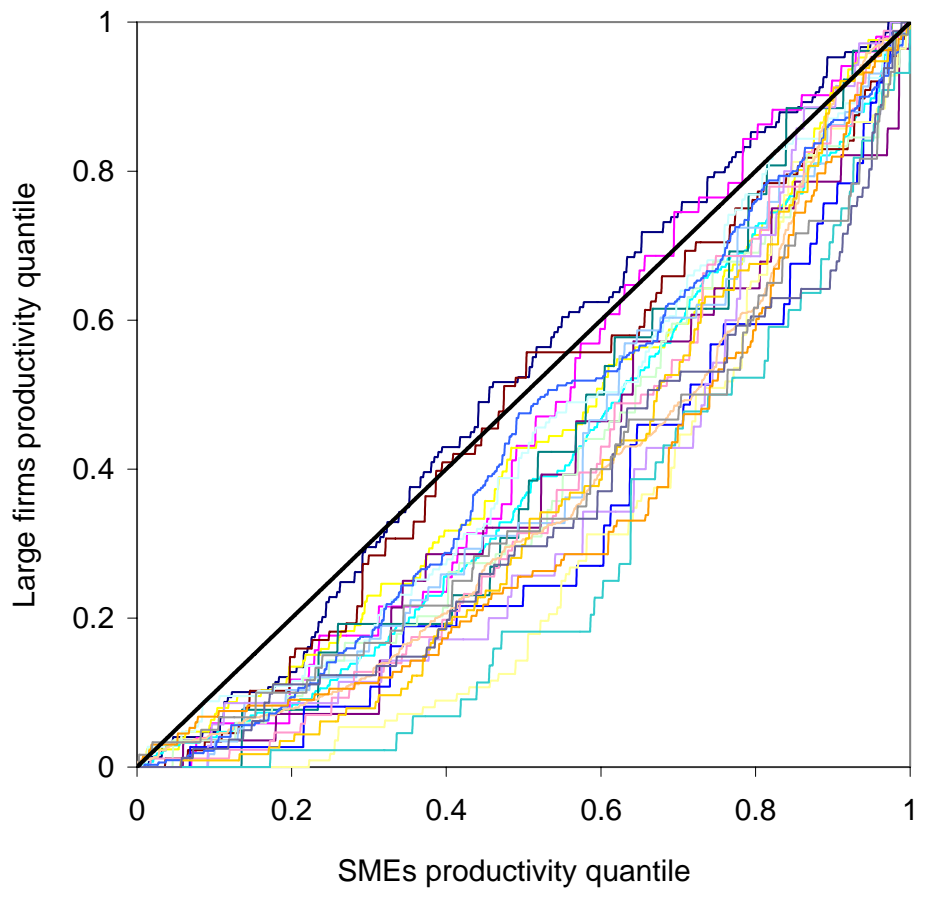

$$
\begin{aligned}
& \text { - Argentina } \\
& \text { - Bolivia } \\
& \text { Colombia } \\
& \text { - Mexico } \\
& \text { - Panama } \\
& \text { - Peru } \\
& \text { - Paraguay } \\
& \text { - Uruguay } \\
& \text { Chile } \\
& \text { Ecuador } \\
& \text { El Salvador } \\
& \text { Honduras } \\
& \text { - Guatemala } \\
& \text { - Nicaragua } \\
& \text { Brazil } \\
& \text { - Chile (2004) } \\
& \text { Costa Rica } \\
& \text { - El Salvador (2003) } \\
& \text { - Guatemala (2003) } \\
& \text { - Honduras (2003) } \\
& \text { - Nicaragua (2003) } \\
& \text { - U[0,1] }
\end{aligned}
$$

Figure 3: The productivity gap: Summary of all countries 


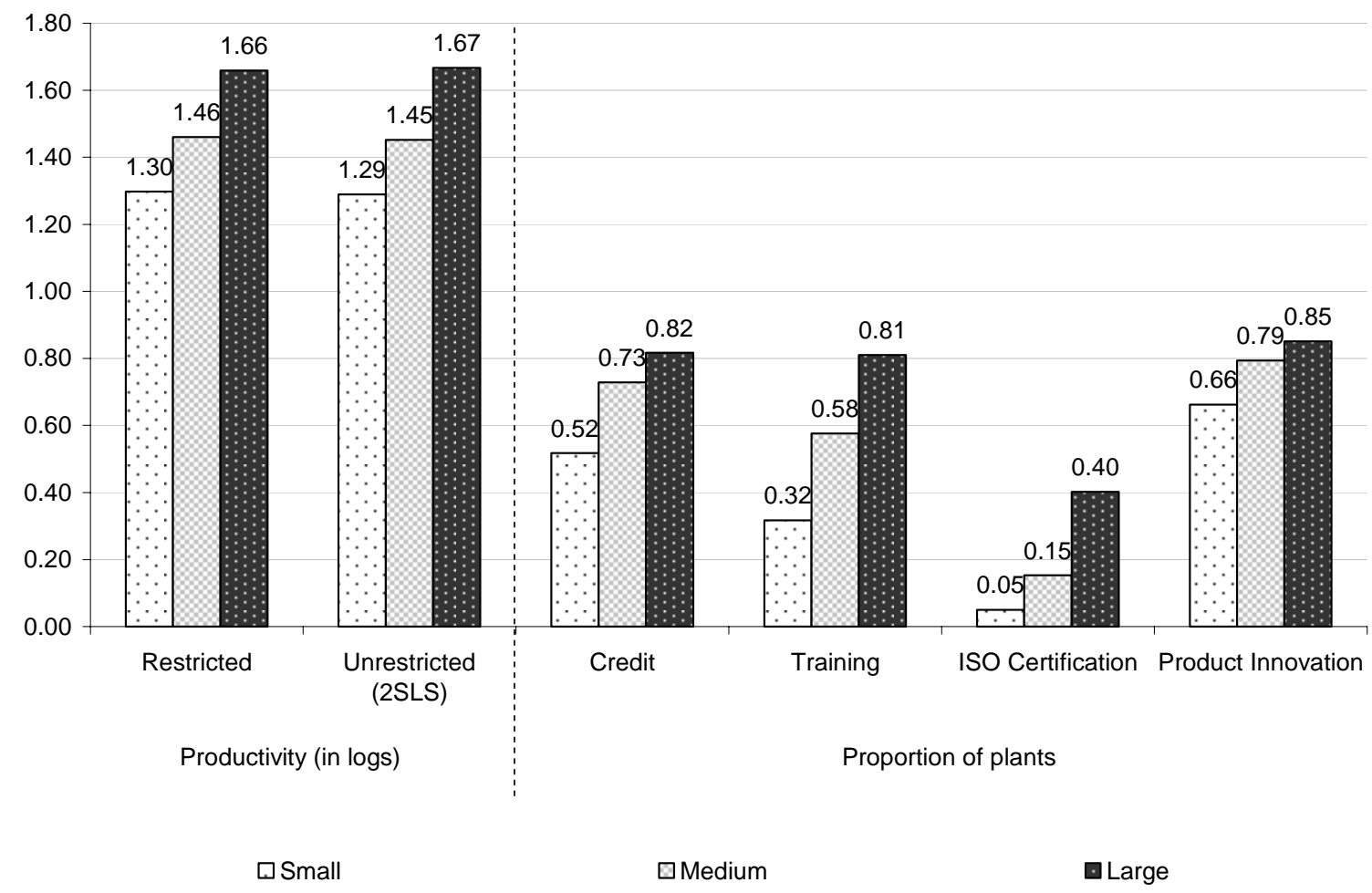

Figure 4: The determinants of the productivity gap 
(a) SME Policy 1

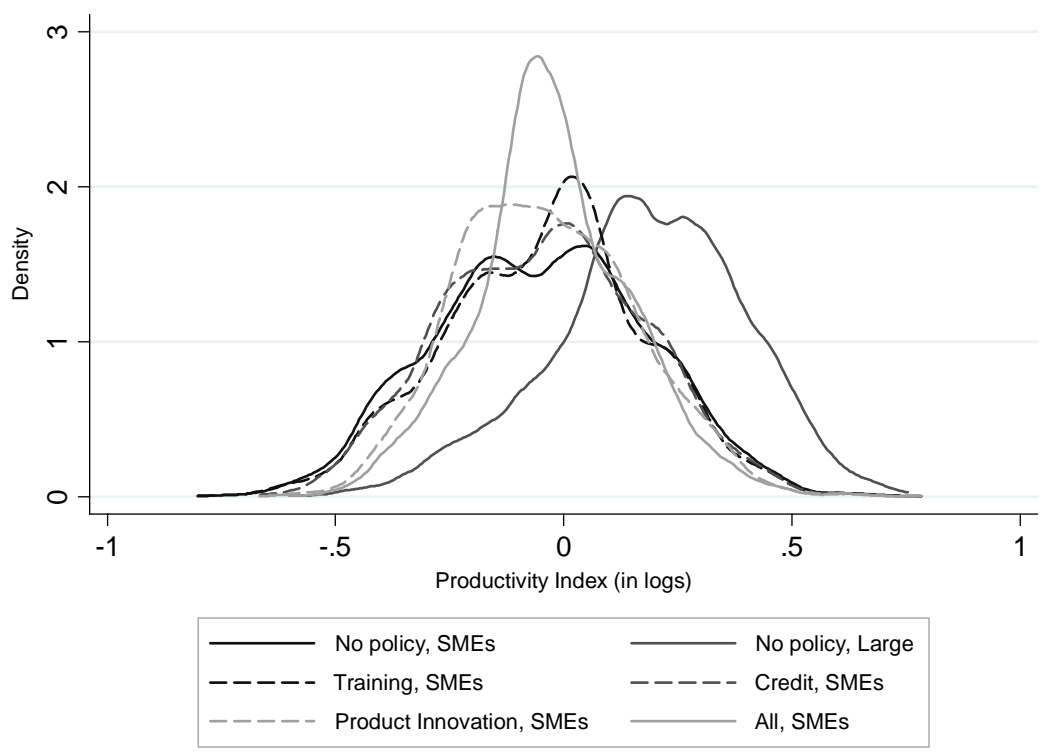

(b) SME Policy 2

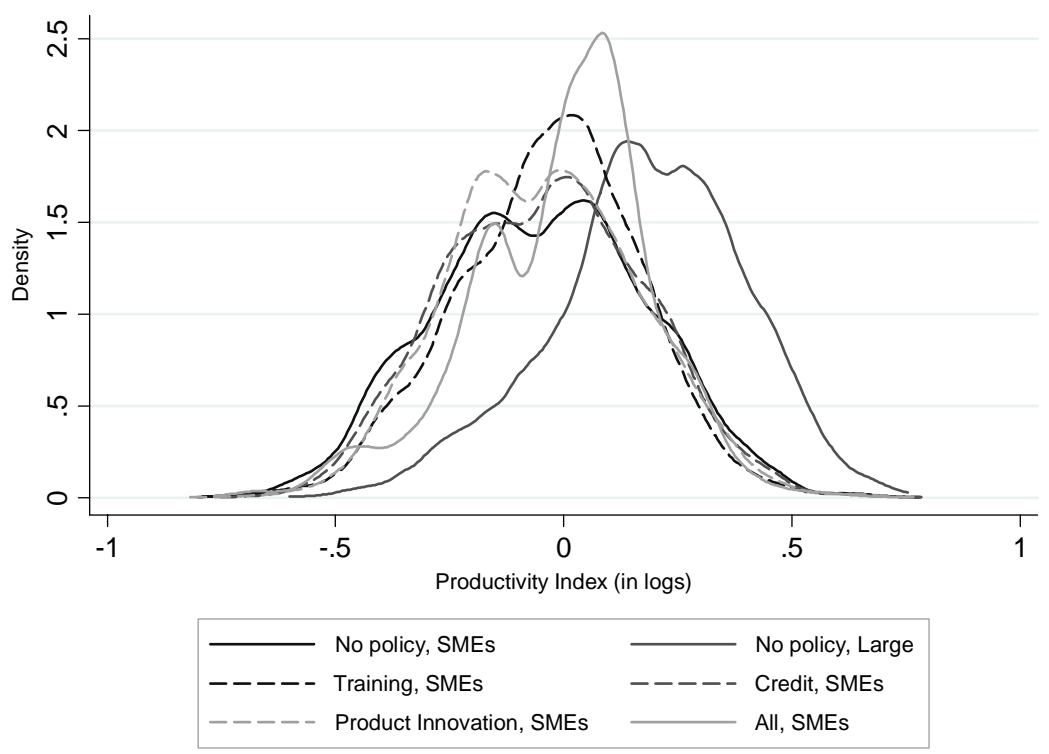

Figure 5: Simulations - The effect on the productivity gap 
(a) Training

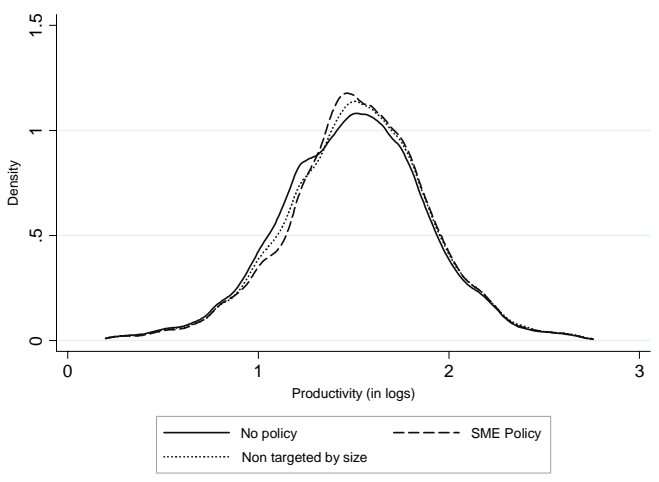

(c) Product Innovation

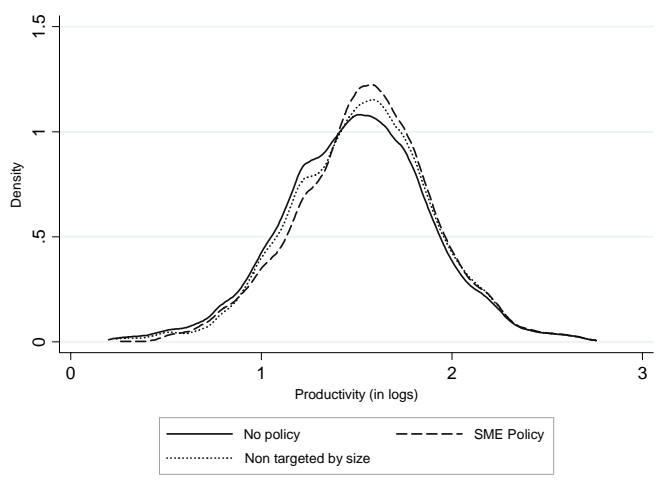

(b) Credit

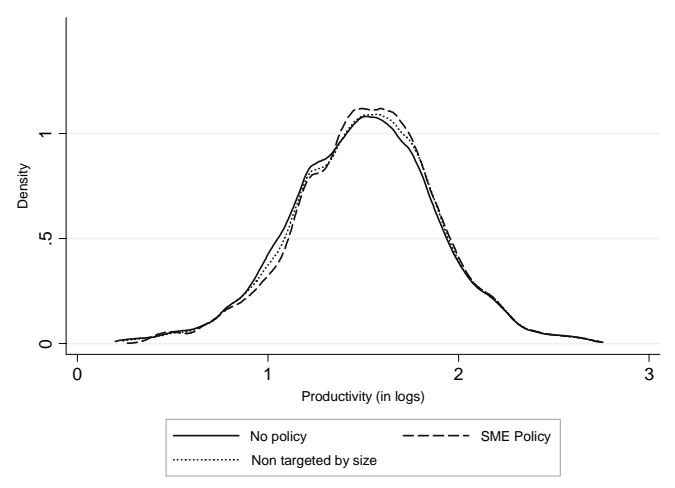

(d) ISO Certification

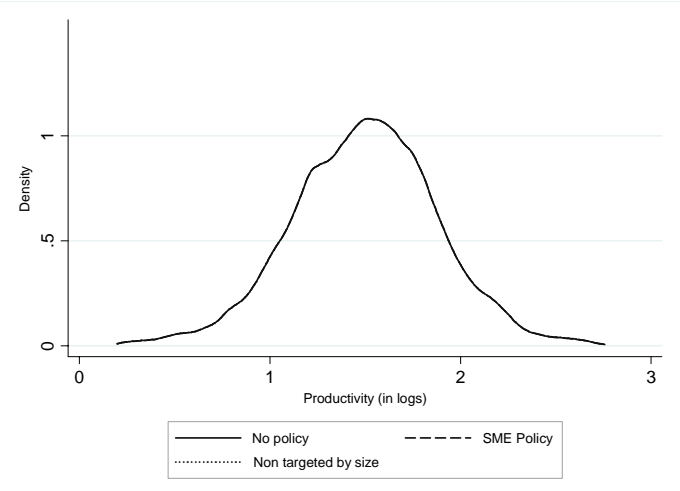

(e) Training, Credit, Product Innovation, and ISO certification

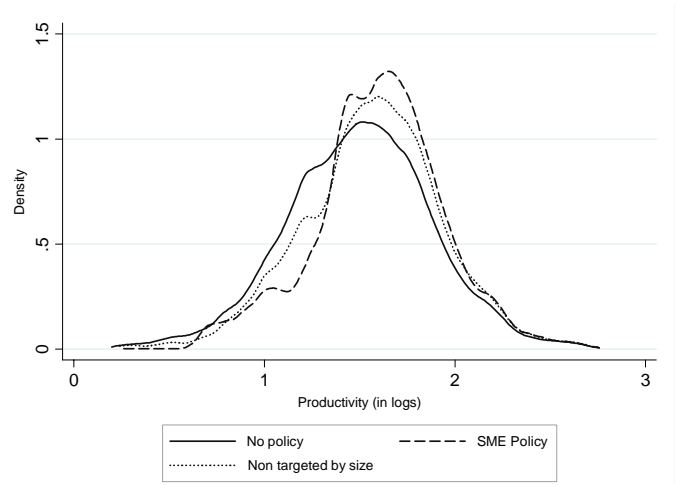

Figure 5: Simulations - SME Policy vs Non-targeted by size policy 
Table 1: Size of the MSME sector in Latin America 
Table 2: Understanding the productivity gap

\section{(a) Regression results}

\begin{tabular}{|c|c|c|c|c|c|c|c|c|}
\hline & \multicolumn{4}{|c|}{ Discrete size definition } & \multicolumn{4}{|c|}{ Continuous size definition } \\
\hline & $\begin{array}{l}\text { Restricted } \\
\text { OLS }\end{array}$ & OLS & $\begin{array}{l}\text { Unrestricted } \\
\text { IV } 1\end{array}$ & IV 2 & $\begin{array}{l}\text { Restricted } \\
\text { OLS }\end{array}$ & OLS & $\begin{array}{l}\text { Unrestricted } \\
\text { IV } 1 \\
\end{array}$ & IV 2 \\
\hline Small firms & $-0.221^{\star \star \star}$ & $-0.153^{\star \star \star}$ & 0.041 & 0.012 & - & - & - & - \\
\hline Medium-sized firms & $-0.151^{\star \star \star}$ & $-0.115^{\star \star \star}$ & -0.026 & -0.036 & - & - & - & - \\
\hline N. of employees & - & - & - & - & $0.060^{\star \star *}$ & $0.039 * * *$ & -0.05 & -0.029 \\
\hline Credit line & - & $0.061^{\star \star \star}$ & 0.327 & $0.181^{*}$ & - & 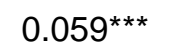 & 0.328 & $0.177^{*}$ \\
\hline Training & - & $0.055^{\star \star \star}$ & 0.212 & $0.234^{\star *}$ & - & $0.054^{\star * \star}$ & 0.293 & $0.290 * \star$ \\
\hline ISO Certification & - & $0.131^{\star \star *}$ & $0.228^{*}$ & $0.221^{\star \star}$ & - & $0.131^{\star \star \star}$ & $0.437^{\star \star \star}$ & $0.322^{\star \star \star}$ \\
\hline Product Innovation & - & 0.000 & 0.303 & $0.275^{\star \star}$ & - & -0.002 & 0.229 & $0.230 *$ \\
\hline Age (in logs) & $0.030 * * *$ & $0.033^{\star * *}$ & $0.030 * *$ & $0.033^{\star \star \star}$ & $0.029 * \star \star$ & $0.033^{\star * \star}$ & $0.033^{\star *}$ & $0.036^{\star \star \star}$ \\
\hline Incorporated Company & $0.091^{\star * *}$ & $0.067^{*}$ & 0.037 & 0.037 & $0.089 * * \star$ & $0.065^{\star}$ & 0.023 & 0.03 \\
\hline Only one proprietary & $-0.138^{\star \star \star}$ & $-0.133^{\star \star \star}$ & $-0.107^{\star \star}$ & $-0.119^{\star \star \star}$ & $-0.130^{\star \star \star}$ & $-0.128^{\star \star \star}$ & $-0.112^{\star \star \star}$ & $-0.121^{\star \star \star}$ \\
\hline One establishment & $-0.119 * \star \star$ & $-0.106^{\star \star \star}$ & $-0.073^{\star *}$ & $-0.074^{\star \star \star}$ & $-0.113^{\star \star \star}$ & $-0.105^{\star \star \star}$ & $-0.069 * \star$ & $-0.077^{\star \star \star}$ \\
\hline $\begin{array}{l}\text { Proportion of Unionized } \\
\text { Workers (C-I-S) }\end{array}$ & $-0.200^{*}$ & $-0.201^{*}$ & $-0.265^{\star \star}$ & $-0.262^{\star \star}$ & -0.142 & -0.146 & -0.203 & $-0.198^{*}$ \\
\hline $\begin{array}{l}\text { Manager's time in } \\
\text { bureaucratic issues (C-I-S) }\end{array}$ & $0.565^{\star \star \star}$ & $0.590 * \star \star$ & $0.673^{\star \star \star}$ & $0.668^{\star * \star}$ & $0.540 * \star$ & $0.555^{\star \star \star}$ & $0.636^{\star \star \star}$ & $0.621^{\star \star *}$ \\
\hline Capacity Utilization (C-I) & $0.012^{\star \star \star}$ & $0.011^{\star \star \star}$ & $0.011^{\star \star \star}$ & $0.011^{\star \star \star}$ & $0.012^{\star \star \star}$ & $0.011^{\star \star \star}$ & $0.010^{\star \star}$ & $0.011^{\star \star \star}$ \\
\hline N. of Obs. & 7715 & 7455 & 7455 & 7455 & 7715 & 7455 & 7455 & 7455 \\
\hline $\begin{array}{l}\text { R-squared } \\
\text { Instruments }\end{array}$ & 0.318 & 0.33 & $\begin{array}{c}0.273 \\
\mathrm{CI} \& \mathrm{IS} \\
\text { average }\end{array}$ & $\begin{array}{c}0.292 \\
\text { CI, IS \& CIS } \\
\text { average }\end{array}$ & 0.318 & 0.33 & $\begin{array}{c}0.255 \\
\mathrm{CI} \& \mathrm{IS} \\
\text { average }\end{array}$ & $\begin{array}{c}0.283 \\
\mathrm{CI}, \mathrm{IS} \& \mathrm{CIS} \\
\text { average }\end{array}$ \\
\hline Sargan (p-value) & & & $2.29(0.68)$ & $3.43(0.90)$ & & & $7.29(0.12)$ & $9.32(0.32)$ \\
\hline Inc. Sargan ( $p$-value) & & & & $1.14(0.12)$ & & & & $2.03(0.27)$ \\
\hline
\end{tabular}




\section{(b) First Stage Statistics}

\begin{tabular}{|c|c|c|c|c|}
\hline & \multicolumn{2}{|c|}{ IV 1} & \multicolumn{2}{|c|}{ IV 2} \\
\hline & Partial R2 & F(p-value) & Partial R2 & $F(p$-value) \\
\hline & \multicolumn{4}{|c|}{ Discrete Size } \\
\hline Credit line & 0.0114 & $10.99(0.000)$ & 0.0306 & $20.31(0.000)$ \\
\hline Training & 0.0114 & $10.86(0.000)$ & 0.0273 & $20.27(0.000)$ \\
\hline $\begin{array}{l}\text { ISO Certification } \\
\text { Product }\end{array}$ & 0.0301 & $27.51(0.000)$ & 0.0689 & $36.07(0.000)$ \\
\hline \multirow[t]{2}{*}{ Innovation } & 0.0129 & $11.27(0.000)$ & 0.0364 & $21.21(0.000)$ \\
\hline & \multicolumn{4}{|c|}{ Continuous Size } \\
\hline Credit line & 0.0122 & $11.56(0.000)$ & 0.031 & $20.16(0.000)$ \\
\hline Training & 0.0121 & $11.71(0.000)$ & 0.0265 & $19.38(0.000)$ \\
\hline $\begin{array}{l}\text { ISO Certification } \\
\text { Product }\end{array}$ & 0.032 & $28.99(0.000)$ & 0.0687 & $36.05(0.000)$ \\
\hline Innovation & 0.0124 & $10.89(0.000)$ & 0.0367 & $21.74(0.000)$ \\
\hline
\end{tabular}

Notes: TBC 
Table 3: The (potential) impact of SME Policy

\begin{tabular}{|c|c|c|c|c|c|c|}
\hline & & Treated & Control & Diff & S.E. & T-stat \\
\hline \multicolumn{7}{|c|}{ (a) Training } \\
\hline \multirow[t]{2}{*}{ All } & Unmatched & 1.509 & 1.364 & 0.145 & 0.019 & 7.610 \\
\hline & ATT & 1.509 & 1.438 & 0.071 & 0.026 & 2.680 \\
\hline \multirow[t]{2}{*}{ Small } & Unmatched & 1.424 & 1.311 & 0.113 & 0.025 & 4.540 \\
\hline & ATT & 1.424 & 1.318 & 0.105 & 0.027 & 3.950 \\
\hline \multirow[t]{2}{*}{ Large } & Unmatched & 1.591 & 1.610 & -0.018 & 0.035 & -0.530 \\
\hline & ATT & 1.591 & 1.520 & 0.072 & 0.042 & 1.700 \\
\hline \multicolumn{7}{|c|}{ (b) Credit Line } \\
\hline \multirow[t]{2}{*}{ All } & Unmatched & 1.501 & 1.304 & 0.197 & 0.020 & 9.790 \\
\hline & ATT & 1.501 & 1.412 & 0.089 & 0.031 & 2.890 \\
\hline \multirow[t]{2}{*}{ Small } & Unmatched & 1.421 & 1.248 & 0.173 & 0.025 & 7.030 \\
\hline & ATT & 1.421 & 1.342 & 0.080 & 0.035 & 2.270 \\
\hline \multirow[t]{2}{*}{ Large } & Unmatched & 1.607 & 1.527 & 0.080 & 0.038 & 2.100 \\
\hline & ATT & 1.607 & 1.496 & 0.110 & 0.057 & 1.950 \\
\hline \multicolumn{7}{|c|}{ (c) ISO Certification } \\
\hline \multirow[t]{2}{*}{ All } & Unmatched & 1.752 & 1.376 & 0.375 & 0.026 & 14.530 \\
\hline & ATT & 1.751 & 1.595 & 0.156 & 0.031 & 4.990 \\
\hline \multirow[t]{2}{*}{ Small } & Unmatched & 1.696 & 1.323 & 0.373 & 0.046 & 8.110 \\
\hline & ATT & 1.696 & 1.466 & 0.230 & 0.048 & 4.750 \\
\hline \multirow[t]{2}{*}{ Large } & Unmatched & 1.776 & 1.516 & 0.260 & 0.032 & 8.130 \\
\hline & ATT & 1.776 & 1.653 & 0.123 & 0.040 & 3.110 \\
\hline \multicolumn{7}{|c|}{ (d) Product Innovation } \\
\hline \multirow[t]{2}{*}{ All } & Unmatched & 1.409 & 1.538 & -0.129 & 0.022 & -5.820 \\
\hline & ATT & 1.409 & 1.395 & 0.013 & 0.035 & 0.390 \\
\hline \multirow[t]{2}{*}{ Small } & Unmatched & 1.310 & 1.467 & -0.158 & 0.027 & -5.900 \\
\hline & ATT & 1.310 & 1.258 & 0.052 & 0.039 & 1.340 \\
\hline \multirow[t]{2}{*}{ Large } & Unmatched & 1.562 & 1.774 & -0.212 & 0.040 & -5.260 \\
\hline & ATT & 1.562 & 1.635 & -0.073 & 0.069 & -1.050 \\
\hline
\end{tabular}


Table 4: Simulations - SME Policy vs Non-Targeted by Size Policy

\begin{tabular}{|c|c|c|c|c|}
\hline & \multirow{2}{*}{$\begin{array}{l}\text { Impact on aggregate } \\
\text { productivity }\end{array}$} & \multicolumn{3}{|c|}{ Percentage of impact explained by } \\
\hline & & Within-firms & Between-firms & Cross-firms \\
\hline \multicolumn{5}{|l|}{ SME Policy } \\
\hline Credit & $4.7 \%$ & $15.3 \%$ & $90.6 \%$ & $-6.0 \%$ \\
\hline Training & $4.9 \%$ & $17.8 \%$ & $86.7 \%$ & $-4.4 \%$ \\
\hline Product innovation & $5.0 \%$ & $20.4 \%$ & $84.9 \%$ & $-5.3 \%$ \\
\hline ISO & $4.5 \%$ & $0.0 \%$ & $100.0 \%$ & $0.0 \%$ \\
\hline All & $5.7 \%$ & $45.4 \%$ & $65.5 \%$ & $-10.9 \%$ \\
\hline \multicolumn{5}{|c|}{ Non-Targeted by Size } \\
\hline Credit & $5.9 \%$ & $39.7 \%$ & $66.7 \%$ & $-6.4 \%$ \\
\hline Training & $6.6 \%$ & $40.2 \%$ & $58.9 \%$ & $0.8 \%$ \\
\hline Product innovation & $6.9 \%$ & $51.0 \%$ & $56.3 \%$ & $-7.3 \%$ \\
\hline ISO & $4.5 \%$ & $0.8 \%$ & $99.1 \%$ & $0.1 \%$ \\
\hline All & $10.5 \%$ & $81.5 \%$ & $26.2 \%$ & $-7.7 \%$ \\
\hline
\end{tabular}


Table 5: Total number of observations by country and size

\begin{tabular}{lrrrr}
\hline \hline & Small & Medium & Large & Total \\
\hline Argentina & 276 & 280 & 170 & 726 \\
Bolivia & 196 & 147 & 58 & 401 \\
Colombia & 329 & 254 & 66 & 649 \\
Mexico & 562 & 348 & 246 & 1,156 \\
Panama & 120 & 89 & 26 & 235 \\
Peru & 147 & 139 & 73 & 359 \\
Paraguay & 192 & 188 & 46 & 426 \\
Uruguay & 185 & 156 & 48 & 389 \\
Venezuela & 177 & 75 & 30 & 282 \\
Chile & 205 & 306 & 173 & 684 \\
Ecuador & 152 & 150 & 85 & 387 \\
El Salvador & 189 & 166 & 110 & 465 \\
Honduras & 139 & 72 & 50 & 261 \\
Guatemala & 130 & 125 & 71 & 326 \\
Nicaragua & 234 & 110 & 21 & 365 \\
Brazil & 294 & 886 & 455 & 1,635 \\
Chile (2004) & 182 & 271 & 235 & 688 \\
Costa Rica & 217 & 87 & 39 & 343 \\
Ecuador (2003) & 142 & 217 & 80 & 439 \\
El Salvador (2003) & 191 & 177 & 97 & 465 \\
Guatemala (2003) & 194 & 146 & 95 & 435 \\
Guyana & 85 & 56 & 13 & 154 \\
Honduras (2003) & 228 & 114 & 108 & 450 \\
Nicaragua (2003) & 288 & 128 & 36 & 452 \\
Peru (2002) & 76 & 33 & 13 & 122 \\
& & & & \\
Total LAC & $\mathbf{5 , 1 3 0}$ & $\mathbf{4 , 7 2 0}$ & $\mathbf{2 , 4 4 4}$ & $\mathbf{1 2 , 2 9 4}$ \\
\hline \hline
\end{tabular}

Note: Some firms do not report the number of employees and therefore it is not possible to construct the size variable. The total number of observations is 12,845 . 
Table 6: Total number of observations by country and industry

\begin{tabular}{lrrrrr}
\hline \hline & $\begin{array}{r}\text { Food and } \\
\text { Beverages }\end{array}$ & $\begin{array}{r}\text { Textiles } \\
\text { and } \\
\text { Apparels }\end{array}$ & $\begin{array}{r}\text { Chemical } \\
\text { Products }\end{array}$ & $\begin{array}{r}\text { Other } \\
\text { manufactured } \\
\text { products }\end{array}$ & Total \\
\hline Argentina & 167 & 236 & 67 & 276 & 746 \\
Bolivia & 123 & 121 & 59 & 106 & 409 \\
Colombia & 154 & 319 & 160 & 16 & 649 \\
Mexico & 158 & 317 & 169 & 517 & 1,161 \\
Panama & 69 & 22 & 12 & 140 & 243 \\
Peru & 120 & 155 & 83 & 3 & 361 \\
Paraguay & 93 & 63 & 108 & 176 & 440 \\
Uruguay & 119 & 118 & 122 & 37 & 396 \\
Venezuela & 72 & 59 & 15 & 137 & 283 \\
Chile & 160 & 121 & 74 & 342 & 697 \\
Ecuador & 105 & 71 & 97 & 121 & 394 \\
El Salvador & 131 & 139 & 29 & 168 & 467 \\
Honduras & 83 & 39 & 22 & 119 & 263 \\
Guatemala & 90 & 83 & 15 & 140 & 328 \\
Nicaragua & 83 & 28 & 24 & 230 & 365 \\
Brasil & 127 & 721 & 84 & 709 & 1,641 \\
Chile (2004) & 215 & 0 & 136 & 337 & 688 \\
Costa Rica & 42 & 57 & 0 & 244 & 343 \\
Ecuador (2003) & 113 & 97 & 89 & 154 & 453 \\
El Salvador (2003) & 114 & 140 & 48 & 163 & 465 \\
Guatemala (2003) & 94 & 139 & 32 & 170 & 435 \\
Guyana & 87 & 19 & 5 & 52 & 163 \\
Honduras (2003) & 116 & 99 & 19 & 216 & 450 \\
Nicaragua (2003) & 84 & 109 & 34 & 225 & 452 \\
Peru (2002) & 37 & 250 & 67 & 199 & 553 \\
Total LAC & & & & & \\
\hline \hline & $\mathbf{2 1 5 6}$ & $\mathbf{3 , 5 2 2}$ & $\mathbf{1 , 5 7 0}$ & $\mathbf{4 , 9 9 7}$ & $\mathbf{1 2 , 8 4 5}$ \\
\hline
\end{tabular}


Table 7: Testing for Constant Returns to Scale (CRS)

\begin{tabular}{|c|c|c|c|c|c|}
\hline & \multicolumn{3}{|c|}{ Input-output elasticities } & \multirow{2}{*}{$\begin{array}{l}\text { Returns to } \\
\text { scale } \\
\text { parameter }\end{array}$} & \multirow{2}{*}{$\begin{array}{c}\text { F (p-value) } \\
\text { Ho: CRS }\end{array}$} \\
\hline & Labor & Materials & Capital & & \\
\hline \multicolumn{6}{|l|}{ All } \\
\hline Cost shares & 0.347 & 0.580 & 0.073 & 1.000 & - \\
\hline Cobb-Douglas & 0.393 & 0.525 & 0.126 & 1.044 & $5.88(0.015)$ \\
\hline \multicolumn{6}{|c|}{ Food and Beverages } \\
\hline Cost shares & 0.293 & 0.623 & 0.084 & 1.000 & - \\
\hline Cobb-Douglas & 0.402 & 0.492 & 0.149 & 1.043 & $5.92(0.015)$ \\
\hline \multicolumn{6}{|c|}{ Textiles and Apparels } \\
\hline Cost shares & 0.399 & 0.541 & 0.060 & 1.000 & - \\
\hline Cobb-Douglas & 0.424 & 0.473 & 0.137 & 1.034 & $3.72(0.054)$ \\
\hline \multicolumn{6}{|l|}{ Chemicals } \\
\hline Cost shares & 0.305 & 0.623 & 0.071 & 1.000 & - \\
\hline Cobb-Douglas & 0.390 & 0.535 & 0.130 & 1.055 & $9.11(0.002)$ \\
\hline \multicolumn{6}{|c|}{ Other manufacturing } \\
\hline Cost shares & 0.356 & 0.568 & 0.076 & 1.000 & - \\
\hline Cobb-Douglas & 0.345 & 0.588 & 0.098 & 1.032 & $3.15(0.076)$ \\
\hline
\end{tabular}

Notes: The estimation of the production function of all industries includes size, industry, and country dummies, age (in logs), the unionization level (at the CIS level), manager's time dealing with bureaucracy (at the CIS level), capacity utilization (at CI level), and dummy variables for listed companies, firms with only one proprietary, firms with only one establishment. The equation estimated to obtain the coefficient of each industry is the same plus the interaction between inputs and industry dummies. 